\title{
Offshoring in a Knowledge Economy
}

\section{Citation}

Antras, Pol, Luis Garicano, and Esteban Rossi-Hansberg. 2006. Offshoring in a knowledge economy. Quarterly Journal of Economics 121(1): 31-77.

\section{Published Version}

http://dx.doi.org/10.1162/qjec.2006.121.1.31

\section{Permanent link}

http://nrs.harvard.edu/urn-3:HUL.InstRepos:3196323

\section{Terms of Use}

This article was downloaded from Harvard University's DASH repository, and is made available under the terms and conditions applicable to Other Posted Material, as set forth at http:// nrs.harvard.edu/urn-3:HUL.InstRepos:dash.current.terms-of-use\#LAA

\section{Share Your Story}

The Harvard community has made this article openly available.

Please share how this access benefits you. Submit a story.

Accessibility 


\title{
OFFSHORING IN A KNOWLEDGE ECONOMY*
}

\author{
Pol ANTRÀs \\ Luis GaRicano \\ Esteban Rossi-Hansberg
}

\begin{abstract}
How does the formation of cross-country teams affect the organization of work and the structure of wages? To study this question, we propose a theory of the assignment of heterogeneous agents into hierarchical teams, where less skilled agents specialize in production and more skilled agents specialize in problem solving. We first analyze the properties of the competitive equilibrium of the model in a closed economy, and show that the model has a unique and efficient solution. We then study the equilibrium of a two-country model (North and South), where countries differ in their distributions of ability, and in which agents in different countries can join together in teams. We refer to this type of integration as globalization. Globalization leads to better matches for all southern workers but only for the best northern workers. As a result, we show that globalization increases wage inequality among nonmanagers in the South, but not necessarily in the North. We also study how globalization affects the size distribution of firms and the patterns of consumption and trade in the global economy.
\end{abstract}

\section{INTRODUCTION}

A number of recent technological ${ }^{1}$ and institutional ${ }^{2}$ developments have blurred the borders between national labor markets and have allowed for the formation of international teams. These developments have altered what teams of agents can do at a distance. Some tasks such as data entry in consumer banking, software upgrades and maintenance, low-level customer handling in call centers, or standardized manufacturing processes, are now frequently done offshore. Other, more knowledge-intensive, tasks (such as data manipulation, software development, higher-end sales and service, and $\mathrm{R} \& \mathrm{D}$ and product design in manufacturing industries) continue to be undertaken domestically. Broadly, routine tasks are offshored, while more complex tasks are done domestically. Thus, the traditional vertical division of labor within a team, whereby some low skill agents (workers) under-

* We thank several colleagues and seminar participants at various institutions, as well as the Editor and two anonymous referees for very useful comments.

1. Improvements in information technology have reduced the cost of international data and voice transfer from prohibitively expensive to levels that are virtually identical to within-country communication costs.

2. Recent political and economic reforms in China, India, and Eastern Europe have substantially liberalized economic activity. Meanwhile, the worldwide deregulation and competition in the telecommunications industry has contributed substantially to the drop in communication costs.

$\odot 2006$ by the President and Fellows of Harvard College and the Massachusetts Institute of Technology.

The Quarterly Journal of Economics, February 2006 
take routine tasks and the highest skill agents (managers) specialize in knowledge-intensive tasks, can now take place across countries.

In our view, what is important about this new division of labor is that it alters the feasible matches between agents' skill types. High skill agents in more developed countries can leverage their knowledge at lower cost by working with cheaper labor on routine tasks, and the better workers in less developed countries are able to become part of international high value added teams.

In this paper we present a simple framework that puts agent skill heterogeneity and matching at the center of the analysis. By allowing us to analyze changes in matching and in the supporting earnings functions, our framework allows us to examine the impact of offshoring on wages, on occupational choices (production versus knowledge jobs), and (as matches are "many-to-one") on the distribution of firm sizes.

We model an economy in which production requires physical inputs and knowledge, and where a continuum of agents with heterogenous abilities sorts into teams competitively. Agents of different skill levels form teams. Less skilled agents (workers) specialize in production work and deal with routine tasks; while the most skilled agents specialize in knowledge-intensive tasks (managers). Relative to less skilled managers, better managers are able to increase more the productivity of all the workers in their team, as they are able to solve a wider range of the problems their team confronts in production. Better production workers allow individuals to manage larger teams, as workers can solve more problems by themselves and require less help. This results in a complementarity between manager and worker ability that determines the identity of agents working and managing different teams. It also determines, through comparative advantage, the occupational choice of agents. More able agents, although more productive as production workers, want to set up their own firms and manage their own teams of workers, instead of working for other managers.

To study the impact of the formation of international teams in this economy, we study a simple one-sector, two-country model in which countries differ only in their skill distributions. In particular, one country, the North, has a distribution of skills with a relatively high mean, while the other country, the South, has a distribution of skills with a relatively low mean. In our model, the "skill overlap" implied by these skill differences is captured by a 
single parameter, which plays a crucial role in the analysis. The other key parameter in our model is the cost of communicating knowledge within teams (i.e., the state of communication technology), which determines the extent to which managers can leverage their knowledge via larger teams.

We initially study the case in which cross-country teams are prohibitively expensive, so that the equilibria in the North and in the South correspond to those of two closed economies. We then compare these equilibria to that of a perfectly integrated international economy, where cross-border teams are as expensive as local ones. We refer to this type of integration as "globalization."

We first show that globalization leads to the formation of international teams in which northern managers supervise teams of southern workers: offshoring. Offshoring thus allows for the geographic separation of production and problem solving, and the delocation of physical production toward the South. It leads to the creation of routine jobs and an increase in production in the South, and to the creation of knowledge-intensive jobs, or firms, and a decrease in production in the North. This implies that the pattern of trade is such that the South is a net exporter of physical goods, while the North is a net exporter of knowledge services.

Globalization also affects the level and structure of earnings of individuals, both in the North and in the South. We first show that our model is consistent with the empirical regularity that southern workers employed in multinational firms receive wages that are on average higher than those received by workers employed in domestic firms (see Aitken, Hanson, and Harrison [1996] for empirical evidence). We next analyze how globalization affects income inequality within each of the two countries. We show that globalization leads to an increase in within-worker wage inequality, that is wage inequality among nonmanagers, in the South. This prediction is consistent with the findings of several empirical studies (e.g., Feenstra and Hanson [1997], Goldberg and Pavcnik [2004], and references therein). These findings have received considerable attention in the international trade literature since they cannot be easily rationalized with standard factor proportions trade frameworks. Our theory predicts an increase in withinworker inequality in the South as a result of changes in matching: globalization improves the quality of the managers with whom southern workers are matched, thus raising the productivity of these workers, and thereby leading to an increase in their marginal 
return to skill. This effect is reinforced by an occupational choice effect: more agents become workers, hence increasing the range of abilities in the worker skill distribution.

The effect on within-worker wage inequality in the North is more complicated. On the one hand, low skill workers in the North face increased competition from southern workers, and this tends to reduce their marginal return to skill. On the other hand, our model highlights a new force leading to an increase in withinworker wage inequality in the North. When more low skill agents are available, the time of high skill managers becomes more scarce, and workers who are better able to economize on this time become relatively more valuable. As a result, the value of more skilled workers relative to less skilled ones increases, as does the difference between the ability of the managers they are matched with. When either the skill overlap or communication costs are sufficiently low, so that high skill managers are particularly valuable and scarce, this last effect dominates, and globalization increases wage inequality not only in the South but also in the North. Conversely, when communication costs and the skill overlap are sufficiently large, the former effect dominates, and offshoring is associated with lower wage inequality in the North. This may help rationalize the findings of Feenstra and Hanson [1996b, 1999] that offshoring raised wage inequality in the United States in the 1980s but not in the 1970s. Our theory suggests that these findings can be explained by lower communication costs and deeper trade integration with less developed countries in the $1980 \mathrm{~s}$ than in the $1970 \mathrm{s.}^{3}$

Which firms engage in offshoring? When the skill overlap is large and communication costs are high, only the most productive and larger firms will engage in offshoring; while, when the skill overlap is small and communication costs are low, the firms that engage in offshoring will actually be the least productive firms, those controlled by the lowest skill managers. More generally, we show that the "quality" of offshoring, as measured by the average skill level of the workers that form international teams relative to the skill level of all southern workers, is weakly increasing in both the skill overlap and communication costs. At the same time, we show that the "quantity" of offshoring, as measured by the

3. The ability of our model to deliver the level of income for all agents in the economy also allows us to identify the winners and losers from globalization. In particular, in subsection IV.B we show that there is always a subset of workers who are hurt by globalization. 
proportion of southern workers who work for northern managers, is instead weakly decreasing in both communication costs and the skill overlap, and converges to zero as the skill distributions completely overlap. We also study how occupational choices, the size distribution of firms, and wage inequality are affected by these same parameters.

One of the advantages of our approach is that offshoring is not only the result of the relative aggregate supply of skills, but rather follows from the competitive sorting of agents with different skill levels into teams. Paraphrasing Sattinger [1993], wages in the economy play an allocative role rather than simply being rewards for the possession of particular characteristics. This allows us to derive conclusions on the characteristics of offshoring firms as well as on the distribution of wages. Most other efforts to understand offshoring do not have this feature. Feenstra and Hanson [1996a, 1997, 2003], for example, assume factor endowments of skilled and unskilled workers in the North and South, and a production function that uses these inputs to produce either intermediate or final goods. ${ }^{4}$ In these models offshoring is the result of foreign direct investment and leads to changes in wage inequality as a result of changes in the sectoral composition of production. Their work is important in that it determines the changes in wages due to these sectoral (in inputs or output) compositional changes. ${ }^{5}$ In general, however, it is silent about changes in wage inequality within narrowly defined sectors as well as on the cross-sectional characteristics of offshoring firms. ${ }^{6}$

Our paper is closely related to the work of Grossman and Maggi [2000] and Kremer and Maskin [2003], in that they also study the relationship between patterns of trade and patterns of matching between the skill of different workers. ${ }^{7}$ Grossman and

4. Feenstra and Hanson [1997] assume that the supply of skill and unskilled labor does respond to relative wages, but they do not model the occupational choice decision or the sorting of agents into production teams.

5. Feenstra and Hanson [2003] stress that these changes in the sectoral composition of production may occur within industries and may therefore not be picked up by industry-level price indices (cf. Lawrence and Slaughter [1993]).

6. Other papers have developed frameworks with similar characteristics that also abstract from the dimensions that we focus on: in particular, Acemoglu [2003], Bernard, Robertson, and Schott [2004], Zhu and Trefler [2005], and Verhoogen [2004].

7. Nocke and Yeaple [2004] present an assignment model of FDI, but focus on the matching between brands of different quality and entrepreneurs of heterogeneous ability. Our paper is also related to a branch in the literature that has stressed the importance of heterogeneity in understanding the differential impact that globalization may have on different types of firms or workers (e.g., Manesse 
Maggi consider the consequences of different types of production functions involving substitutability or complementarity in skills for the patterns of specialization and trade. A maintained assumption in their analysis is that international teams are not allowed to form.

Our work is more closely related to Kremer and Maskin [2003], who study the patterns of trade and wages that result from production functions that are characterized by complementarity between inputs and imperfect substitutability between them. Consistent with any production function that may hope to address within-worker wage inequality, the production function we study involves skill complementarity, imperfect substitutability between workers' skill, and differential sensitivity to the skill of different workers (see Kremer and Maskin [1997]). Our model, however, is novel in four key dimensions. First, following Garicano and Rossi-Hansberg [2005, 2004], it is the only one to involve hierarchical one-to-many matching (rather than one-to-one matching), where a manager is endogenously matched with a potentially large number of workers, and can potentially raise the output of all of them. Second, the identity of managers and workers is endogenous and is the result of an occupational choice decision. Third, the actual team production function results naturally and endogenously from a production process that does not assume skill complementarities, but rather derives them from the specialization of agents in different aspects of the process-production and knowledge. Fourth, the relation between the skill of the manager and that of the worker is mediated by communication technology; that is, the state of communication technology determines the extent to which a manager can leverage his knowledge by communicating it to many or few production workers. As a result of these differences, we are able to move beyond previous contributions in formally analyzing how the process of globalization interacts with the state of communication technologies in determining the worldwide organization of production and the structure of rewards that support it. ${ }^{8}$

and Turrini [2001], Melitz [2003], Helpman, Melitz, and Yeaple [2004], Antràs and Helpman [2004], and Yeaple [2005]).

8. For previous equilibrium models of the allocation of heterogeneous agents to hierarchical teams, but which do not involve matching between workers and managers, see Lucas [1978], Rosen [1982], and Waldman [1984]. 
Our paper differs from Garicano and Rossi-Hansberg [2005] in that we simplify the analysis by taking the skill level of agents as exogenous, and we limit team sizes to two layers. The payoff for this simplification is that we provide a closed-form solution to the model and, most importantly, we are able to study the relationship between matching and wage inequality across countries.

The rest of the paper is organized as follows. Section II presents the basic framework for a closed economy and shows existence, uniqueness, and optimality. Section III constructs an equilibrium in the integrated economy and discusses its basic properties. Section IV discusses the effects of economic integration or globalization. Section V presents comparative statics with respect to communication costs and the skill overlap, and Section VI concludes. All the proofs in the paper are relegated to the Appendix.

\section{The Model}

Agents are endowed with one unit of time and a skill level $z$. The distribution of skills in the population is given by a cumulative distribution function $G(z)$, with density $g(z)$, that for the moment we will assume has support in $[0, \bar{z}]$ with $\bar{z} \leq 1$. Agents rank consumption according to a linear utility function, so they are income maximizers, given that we normalize the price of the only good in the economy to one.

Our theory of the organization of production follows Garicano [2000]. Production is done by teams with one manager and production workers. Workers spend their time producing. While producing, they face a problem that has to be solved for production to happen. If a worker knows the solution to her problem, she solves it and produces one unit of output. If she does not know the solution, she can ask her manager. If the manager knows the solution to the problem, the manager solves it immediately, communicates the solution to the worker, and she produces one unit of output. The manager spends $0<h<1$ units of time communicating what she knows to the worker no matter if she knows the solution to the problem or not. The skill level of an agent determines the set of problems she can solve. An agent with skill $z$ can solve all problems that require knowledge between 0 and $z$. We normalize the set of problems so that the skill level $z$ is also the 
proportion of problems an agent can solve. ${ }^{9}$ Hence, a manager in a team with $n$ workers of skill $z_{p}$ faces the following time constraint:

$$
h\left(1-z_{p}\right) n=1,
$$

and so can deal with $n\left(z_{p}\right)=1 /\left[h\left(1-z_{p}\right)\right]$ workers. ${ }^{10}$ Production in a team formed by a manager with skill level $z_{m}$ and workers with skill $z_{p}$ is therefore given by $z_{m} n\left(z_{p}\right)$. Given wages, managers choose the ability of their workers to maximize rents, ${ }^{11}$

$$
R\left(z_{m}\right)=\max _{z_{p}}\left(z_{m}-w\left(z_{p}\right)\right) n\left(z_{p}\right)=\max _{z_{p}} \frac{z_{m}-w\left(z_{p}\right)}{h\left(1-z_{p}\right)},
$$

subject to

$$
h\left(1-z_{p}\right) n=1 .
$$

The first-order condition of this problem is given by

$$
w^{\prime}\left(z_{p}\right)=\frac{z_{m}-w\left(z_{p}\right)}{1-z_{p}} .
$$

Agents choose whether to become managers or workers so as to maximize their utility, that is, their income. Hence given their ability $z$, they solve $\max \{R(z), w(z)\}$. This implies that the earnings function, the envelope of the wage and rent functions, given occupational choices, will be continuous.

In equilibrium labor markets clear. Namely, at the equilibrium wages and earnings, the supply and demand of production workers equalize at all skill levels. Let $w(\cdot)$ be an equilibrium wage function, and let the equilibrium occupational choice decision be such that agents with skill levels in $\left[0, z^{*}\right]$ become workers and agents in $\left[z^{*}, \bar{z}\right]$ become managers. Agents with knowl-

9. The upper bound $\bar{z}$ thus represents the fraction of problems that the most-skilled agent in the economy can solve.

10. In principle, the interpretation of our technology given in the text requires us to address the stochastic element in the arrival of problems, which could result in congestion and queuing. Doing so would not, we believe, add to the economics of the question at hand. An alternative interpretation, that circumvents the need to address these issues, is that each worker draws a continuum of problems of measure one. Workers then solve the problems that they can, given their skill level, and ask managers for help on the measure of problems that they do not know how to solve. Then, $h$ would be interpreted as the time cost for a manager of helping on a measure one of problems.

11. Note also that we have assumed that a manager with ability $z_{m}$ hires workers of homogeneous ability $z_{p}$. In Antràs, Garicano, and Rossi-Hansberg [2005] we generalize the technology and show that this assumption is without loss of generality. 
edge $z^{*}$ are indifferent. This restriction on equilibrium occupations turns out to be without loss of generality, as Theorem 1 below shows. Let $m(z)$ be the skill level of the manager of a worker with ability $z$. We prove in Theorem 1 that an equilibrium allocation of this economy has to satisfy positive sorting and, therefore, that $m$ is invertible. Then, labor market clearing implies that

$$
\int_{0}^{z_{p}} g(z) d z=\int_{m(0)}^{m\left(z_{p}\right)} n\left(m^{-1}(z)\right) g(z) d z \text { for all } z_{p} \leq z^{*},
$$

where $m^{-1}(z)$ is the ability of the workers hired by a manager of ability $z$. The left-hand side of this equation is the supply of workers between 0 and $z_{p}$. The right-hand side is the demand for workers by managers between $m(0)=z^{*}$ and $m\left(z_{p}\right)$. Market clearing is guaranteed when supply equals demand for every skill level of workers $z_{p}<z^{*}$. Substituting for $n$ and deriving with respect to $z_{p}$, we obtain that, as long as $z<z^{*}$ and $m(z)$ is increasing (positive sorting),

$$
m^{\prime}(z)=h(1-z) \frac{g(z)}{g(m(z))} .
$$

Notice that in this economy positive sorting is always guaranteed because of the complementarity between workers' and managers' talent (see equation (1)). Hence, better workers always work for better managers, a property we will exploit intensively below. This differential equation, together with the two boundary conditions $m(0)=z^{*}$ and $m\left(z^{*}\right)=\bar{z}$, determines the equilibrium assignment function. Notice that the equilibrium assignment of workers to managers can be determined without knowing wages and rents once positive sorting is established. ${ }^{12}$ Note also that since managers lead teams with many workers, matching is many-to-one. This implies that $m$, although single valued, has a slope smaller than $g(z) / g(m(z))$, and so a given mass of workers is matched with a smaller mass of managers.

12. Of course, equilibrium wages and rents sustain this assignment as an equilibrium allocation. We can compute assignments independently of wages since the span of control of managers is a technological restriction of the problem. Managers add agents to their teams until they do not have any time left. If agents could acquire skill, or could work by themselves, this helpful property of our economy would be lost, and the analysis would be much more complicated. Garicano and Rossi-Hansberg [2005, 2004] present closed economy frameworks that incorporate these dimensions. 
A competitive equilibrium in our economy is therefore given by a wage function $w$, a rent function $R$, an assignment function $m$, and occupational choice decisions (summarized by $z^{*}$ ), such that managers maximize rents $\left((2)\right.$ is satisfied and $w^{\prime}\left(z^{*}\right)<$ $\left.R^{\prime}\left(z^{*}\right)\right),{ }^{13}$ agents maximize utility $\left(w\left(z^{*}\right)=R\left(z^{*}\right)\right)$, and labor markets clear ((3) is satisfied together with $m(0)=z^{*}$ and $\left.m\left(z^{*}\right)=\bar{z}\right)$. The following theorem shows that an equilibrium of this economy exists as long as $h$ is lower than a threshold $h * .{ }^{14}$ It also shows that, if an equilibrium exists, it is unique, efficient, exhibits positive sorting, and can be characterized by a threshold $z^{*}$ as we have done so far. On top of this, we can show in general that the earnings function $\max \{R(z), w(z)\}$ is strictly convex in $z$.

Theorem 1. There exists a threshold $h^{*}>0$ such that if $h \in$ $\left[0, h^{*}\right]$ there exists a unique competitive equilibrium of this economy. In equilibrium the set of managers and the set of workers are connected, the equilibrium exhibits positive sorting, and the earnings function is strictly convex. Furthermore, the equilibrium allocation is efficient.

\section{II.A. Equilibrium in the Closed Economy}

Consider a world formed by two independent economies where agents can only form teams with other agents in the same economy. The first one, that we call the North, is exactly as described before but with a uniform distribution of skills in the population, $G_{N}(z)=z$ for $z \in[0,1]$, with density $g_{N}(z)=1$. In the North, the best agents of the economy can therefore solve all the problems that arise in production. The second economy, that we call the South, also has a uniform distribution of skills, but the support of the distribution is the interval $[0, \alpha]$ for $\alpha<1$, with $G_{S}(z)=z / \alpha$ for $z \in[0, \alpha]$, and density $g_{S}(z)=1 / \alpha$. The best agents in the South can thus solve only a fraction $\alpha$ of the problems that they face while producing. The North is, therefore,

13. The second condition is needed to guarantee that managers at $\bar{z}$ do not profit from hiring agents with abilities slightly above $z^{*}$. The condition is necessary given that (2) only holds for $z \in\left(0, z^{*}\right)$ but not for $z^{*}$. Garicano and Rossi-Hansberg [2005] show that this condition would always be satisfied if we were to allow agents to produce individually as well as in teams.

14. The reason that we need to restrict $h$ for an equilibrium to exist is that we do not allow agents to be self-employed. If we were to allow them to work on their own, we could guarantee existence for all $0<h<1$. In the rest of the paper we will analyze the case in which we specify the distribution of abilities to be a piecewise uniform density, and in this case we can show that $h^{*}>0.85$. 
relatively better endowed with skilled agents, but both countries are identical in all other respects, including population size. We will often refer to the parameter $\alpha$ as the skill overlap. The choice of a uniform assumption has the virtue of allowing us to solve the whole model analytically. ${ }^{15}$ It also implies that $h^{*}>0.85$, and so below we will focus only on $h \in[0,0.85]$.

The northern economy is just a special case of the southern economy when $\alpha$ is equal to 1 . Hence, we start by describing an equilibrium in the South. All the expressions are identical for the North if we substitute $\alpha=1$. Using (3) and the boundary condition $m_{S}(0)=z_{S}^{*}$, we obtain that

$$
m_{S}(z)=z_{S}^{*}+h z(1-1 / 2 z),
$$

and, using $m_{S}\left(z_{S}^{*}\right)=\alpha$, we can solve for the threshold ability $z_{S}^{*}$ :

$$
z_{S}^{*}=\frac{1+h-\sqrt{1+h^{2}+2 h(1-\alpha)}}{h} .
$$

That is, all agents with skill between 0 and $z_{S}^{*}$ become workers, and all agents with skill between $z_{S}^{*}$ and $\alpha$ become managers. It is easy to show that $z_{S}^{*}$ increases as communication technology improves; that is, as $h$ declines. Intuitively, now managers can have larger teams, so in equilibrium there are fewer managers and more workers. In an economy with more skilled agents, larger $\alpha, z_{S}^{*}$ is higher. There are two forces that determine this effect. First, as $\alpha$ increases and therefore the density $1 / \alpha$ decreases, given the size of teams, agents with higher skill decide to become workers. Second, the best agents manage larger teams, which reduces the set of managers and increases the set of workers. Thus, an economy with higher $\alpha$ or lower $h$ is an economy in which the skill levels of the agents that become workers is more

15. The distribution of skills across countries depends on both the distribution of innate ability and the technology available to transform endowed innate ability into skills used in production. Start with the same innate distribution of ability in both countries, but let economic, institutional, or cultural factors result in different technologies to transform ability into skill. Suppose that an agent with ability $z$ that goes through, say, the compulsory education system obtains $e_{i} z$ units of marketable skills, $i \in\{S, N\}$, where $e_{N}>e_{S}$ if the North has a better education system. Then, a uniform distribution of innate abilities in both countries with normalized support in $[0,1]$ leads to our assumption on the distributions of skills, after normalizing $e_{N}=1$ and letting $e_{S} / e_{N}=\alpha<1$. Generally, any technology that results in skills that are proportional to the level of ability will imply distributions of skills with supports that overlap only for low skill levels. Some of our results will depend on this property of the distribution of skills. See Garicano and Rossi-Hansberg [2005] for a framework in which agents can choose the amount of skills given their innate ability. 
dispersed. This higher skill dispersion will lead to higher measured within-worker wage inequality. We call this effect the occupational choice effect.

A characteristic of this equilibrium is that, because of positive sorting, more skilled managers lead teams with more skilled workers. Since the size of a firm is uniquely determined by the skill levels of its workers and by an economywide parameter $h$, higher skilled agents work in larger firms. Because managers of these firms have more skill, they solve a larger proportion of the problems they face, and so these firms are more productive: the average product of labor is higher. As we will now see, this will result in both managers and workers in these teams earning more per unit of skill; the wage and rent functions will be convex in the level of skill (see also Theorem 1 above).

Equation (2), together with $w_{S}\left(z_{S}^{*}\right)=R_{S}\left(z_{S}^{*}\right)$, implies that the equilibrium wage function is given by

$$
w_{S}(z)=z_{S}^{*}-\sigma_{S}(1-z)+1 / 2 h z^{2},
$$

where

$$
\sigma_{S}=\frac{h z_{S}^{*}\left(1+1 / 2 h z_{S}^{*}\right)}{1+h-h z_{S}^{*}} .
$$

The slope of the wage function, the marginal return to skill for workers, is thus given by

$$
w_{S}^{\prime}(z)=\sigma_{S}+h z .
$$

Hence the wage function is convex: the marginal return to skill increases with the skill level. This force is captured by the quadratic term $1 / 2 h z^{2}$, and it reflects the imperfect substitutability between workers of different skill-the skill price per unit of skill varies with the skill level. Throughout the paper we refer to this force as the complementarity effect. There is a second determinant of the marginal return to skill, the one given by $\sigma_{S}$, which is determined by the supply and demand of worker skill in equilibrium: the competition effect.

The marginal return to skill can be shown to be an increasing function of $h$. As communication costs decrease, given the threshold $z_{S}^{*}$, team size increases. Since the difference between the skill levels of the managers of two different workers will be smaller the larger are team sizes, complementarity between worker and manager skills implies a decrease in the marginal return to skill: a 
decrease in the complementarity effect. This is reinforced by a second effect resulting from lower communication costs reducing the demand for workers' skills, which reduces their baseline price: a decrease in the competition effect.

The marginal return to skill is also increasing in $\alpha$, since $\sigma_{S}$ is an increasing function of $z_{S}^{*}$ which in turn increases with $\alpha$. In this case the complementarity effect is unchanged. In contrast, the competition effect increases: since agents are more skilled, there are too few workers per manager at the old threshold, which requires raising workers' return to skill in equilibrium. Again, workers are matched with better managers, and this increases the returns to their own skill.

After solving for the distribution of wages, we turn next to the analysis of managerial rents. From equation (1) managerial rents are given by

$$
R_{S}(z)=\frac{z-w_{S}\left(m_{S}^{-1}(z)\right)}{h\left(1-m_{S}^{-1}(z)\right)} .
$$

Using the envelope condition, the marginal return to skill for managers is given by

$$
R_{S}^{\prime}(z)=1 /\left(h\left(1-m_{S}^{-1}(z)\right)\right) .
$$

Given that the assignment function is increasing (positive sorting), the rent function is convex: the marginal return to skill for managers increases with their skill level (see Theorem 1 above). Note also that the marginal return to skill for managers is equal to the number of workers in their team. Hence, every time we derive conclusions about firm size, the same applies for the marginal return to skill of managers.

A worker of ability $z$ works for a manager with ability $m(z)$. This means that the total output produced by this worker is given by $m(z)$. Total production in the South is therefore given by ${ }^{16}$

$$
Y_{S}=\int_{0}^{z_{S}^{*}} m_{S}(z) g_{S}(z) d z=\frac{1}{6 \alpha} z_{S}^{* 2}\left(6+3 h-h z_{S}^{*}\right) .
$$

It is easy to verify that $Y_{S}$ decreases with $h$ and increases with $\alpha$. The reasoning is simple: the larger is $h$, the higher are commu-

16. Equivalently, output may be calculated as the integral over managerial skill of the production function, $n\left(m^{-1}(z)\right) z$. Both expressions yield the same result, as one results from a change of the variable of integration in the other. 
nication costs, the less managers can leverage their knowledge, and the lower is the implied average productivity. As $\alpha$ increases, the average skill level in the economy increases, which also leads to larger output.

\section{Equilibrium in the World Economy}

Consider a world economy formed by the two countries described above, North and South. In the world equilibrium, agents can form production teams with agents in their own country or with agents in the other country. We assume that the cost of communicating the solution to a problem, $h$, is the same whether communication happens between agents in the same or in different countries. ${ }^{17}$

The equilibrium in the world economy is similar to an equilibrium in the individual countries once we adjust the distribution of talent in the population. The distribution of skills in the world population is given by the sum of the distribution of skills in the South and in the North (and so it is not a probability distribution since it integrates to 2), namely,

$$
g_{W}(z)= \begin{cases}(1+\alpha) / \alpha & \text { if } 0<z<\alpha \\ 1 & \text { if } \alpha<z<1\end{cases}
$$

The construction of an equilibrium in this economy parallels the one for a closed economy with one caveat. Since the density of skills in the world is not continuous, the derivative of the assignment function is not continuous. However, an equilibrium allocation must be such that the earnings function is continuous and differentiable for all $z$ except at the threshold that divides workers and managers, at which it is not differentiable, just as in the closed economy. If this condition was not satisfied, some managers and workers would have incentives to form new teams. This implies that the assignment function is continuous and Theorem 1 applies unchanged for the world economy.

17. We could add an extra cost of communicating with agents in another country. However, this extra cost would then influence the formation of international teams directly and would open a wedge between wages in different countries, thereby greatly complicating the analysis of the economic forces in the equilibrium of our setup. Furthermore, this added complexity would be associated with relatively small gains in terms of new results or economic insights, unless we allowed for multiple layers of management within a firm. We develop some of these extensions in Antràs, Garicano, and Rossi-Hansberg [2006] 
Depending on the value of $h$ and $\alpha$, we can show that there are two types of equilibria in the world. The first one is an equilibrium in which all agents in the South are workers. Since there are no managers in the South, all of them work for northern managers. That is, they all work in international teams. Positive sorting implies that, because they are the lowest quality workers in the world (there is an identical set of workers in the North plus some more skilled ones), they work for the worst managers in the North. Hence, international teams are associated with the worst workers and managers in the world. We call this the Low Quality Offshoring Equilibrium ( $L Q E$ ).

The second type of equilibrium is one in which some of the agents in the South are managers. This equilibrium features the less skilled workers in the South working for southern managers, and the more skilled ones working for the best managers in the North. We call this the High Quality Offshoring Equilibrium $(H Q E){ }^{18}$ All our results are derived under the assumption that international teams are formed only if managers strictly prefer to hire foreign workers than domestic ones. ${ }^{19}$

In general, the set of parameter values that determines the boundary between these two equilibria is a nonlinear function of $h$ and $\alpha$ that we will determine below, and which we plot in Figure I. We analyze each equilibrium in turn.

\section{III.A. Low Quality Offshoring Equilibrium}

Denote by $z_{W L}^{*}$ the threshold that separates the ability of the agents who choose to be workers or managers in a LQE. In order for the world equilibrium to be a LQE, it must be the case that $\alpha<z_{W L}^{*}$ (i.e., all agents in the South are workers). For an assignment to satisfy the world labor market equilibrium condition it has to satisfy (3) or, in this case,

$$
m^{\prime}(z)= \begin{cases}((1+\alpha) / \alpha) h(1-z) & \text { if } 0<z<\alpha \\ h(1-z) & \text { if } \alpha<z<z_{W L}^{*} .\end{cases}
$$

Equilibrium in the labor market also implies that $m(0)=z_{W L}^{*}$ and $m\left(z_{W L}^{*}\right)=1$. In order for the wage function to be differentiable (see (2)), the assignment function has to be continuous at

18. In Section $V$ we will define a precise measure of offshoring quality, and we will show that in a LQE the quality of offshoring is always lower than in a HQE, thus justifying the names chosen for the two types of world equilibria in our setup. 19. We are effectively selecting the equilibrium with the least amount of offshoring. This is analogous to the approach in Helpman [1984]. 


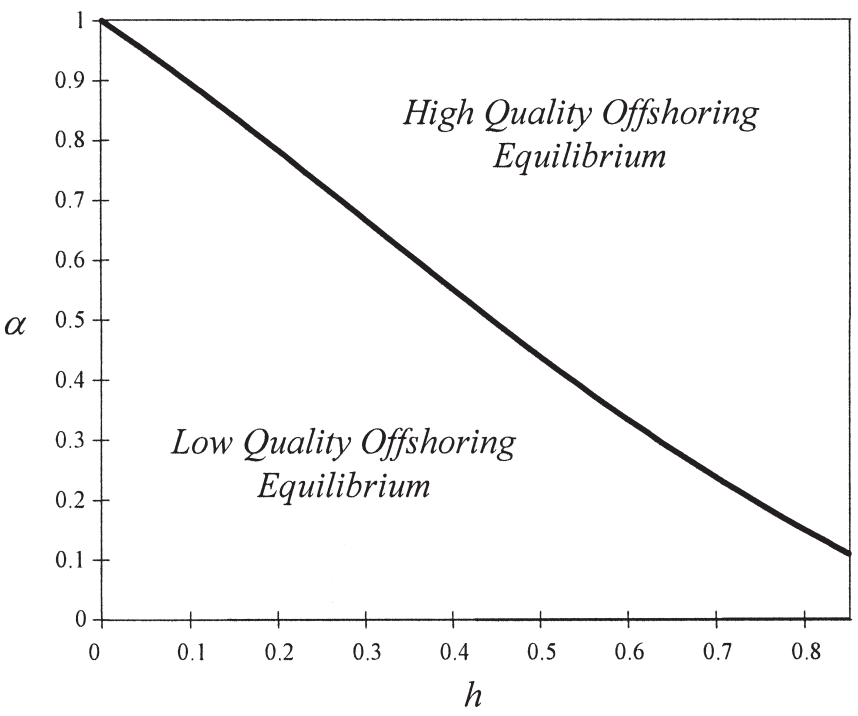

FIGURE I

Types of Equilibria

all $z<z_{W L}^{*}$, and in particular at $\alpha$. This characteristic of the equilibrium allocation provides another boundary condition of the problem. Using the two differential equations and the three boundary conditions, we can solve for the assignment function,

(9) $m_{W L}(z)= \begin{cases}z_{W L}^{*}+((1-\alpha) / \alpha) h z(1-1 / 2 z) & \text { if } 0<z<\alpha \\ z_{W L}^{*}+h(1-1 / 2 \alpha)+h z(1-1 / 2 z) & \text { if } \alpha<z<z_{W L}^{*},\end{cases}$

as well as for the threshold

$$
z_{W L}^{*}=\frac{1+h-\sqrt{1+h^{2}(3-\alpha)}}{h} .
$$

Again, simple differentiation verifies that $z_{W L}^{*}$, the set of workers in the world, decreases with $h$ and increases with $\alpha$, where the intuition is similar to the one for the closed economy. Note that the assignment function is continuous, but not differentiable, at $\alpha$.

In order for the world to be in a $\mathrm{LQE}$, we need to guarantee that $z_{W L}^{*}>\alpha$ or

$$
h<2(1-\alpha) /\left(2+\alpha-\alpha^{2}\right) .
$$

The right-hand side of the inequality is decreasing in $\alpha$ and is equal to zero for $\alpha=1$ and equal to one for $\alpha=0$. This condition, 
with equality, is the curve that separates the parameter set where we obtain each equilibrium and that was plotted in Figure I.

Maximization of rents by managers implies that wages have to satisfy (2). Furthermore, in order for agents not to have incentives to join other firms in the economy, which would be willing to hire them, we also know that the earnings function has to be continuous. In particular, the wage function has to be continuous at $\alpha$ and wages and rents have to be equal at $z_{W L}^{*}$. The latter condition is given by $w_{W L}\left(z_{W L}^{*}\right)=R_{W L}\left(z_{W L}^{*}\right)$. Combining all these conditions, we obtain

$$
\begin{aligned}
& w_{W L}(z) \\
& = \begin{cases}z_{W L}^{*}-\sigma_{1 L}(1-z)+1 / 2((1+\alpha) / \alpha) h z^{2} & \text { if } 0<z<\alpha \\
z_{W L}^{*}+h(1-1 / 2 \alpha)-\sigma_{2 L}(1-z)+1 / 2 h z^{2} & \text { if } \alpha<z<z_{W L}^{*},\end{cases}
\end{aligned}
$$

where

$$
\sigma_{1 L}=\frac{h z_{W L}^{*}\left(1+h+1 / 2 h z_{W L}^{*}\right)-1 / 2 h^{2} \alpha}{1+h-h z_{W L}^{*}}
$$

and

$$
\sigma_{2 L}=\sigma_{1 L}+h .
$$

Note that at $z_{W L}^{*}$

$$
w_{W L}^{\prime}\left(z_{W L}^{*}\right)=\frac{1-w_{W L}\left(z_{W L}^{*}\right)}{1-z_{W L}^{*}} \leq \frac{1}{h}=R_{W L}^{\prime}\left(z_{W L}^{*}\right),
$$

for $h<h^{*}$ (see the proof of Theorem 1). Hence, the earnings function has a kink, a nondifferentiability, at $z_{W L}^{*}$. This implies that, given that the wage and rent functions are convex, the marginal return to skill is larger for managers than for workers.

Figure II summarizes what we have discussed about a LQE. Agents with skill in $[0, \alpha]$ in the South and North work for northern managers with skill in $\left[z_{W L}^{*}, m_{W L}(\alpha)\right]$. Agents in the North with skill in $\left[\alpha, z_{W L}^{*}\right]$ work for managers in the North with skill in $\left[m_{W L}(\alpha), 1\right]$. The wage function of all workers in the world, and the rent function of northern managers, is a continuous and differentiable function of skill. The marginal return to skill of managers is larger than that of workers.

\section{III.B. High Quality Offshoring Equilibrium}

A HQE is such that the highest skilled agents in the South decide to become managers. If we denote by $z_{W H}^{*}$ the threshold 


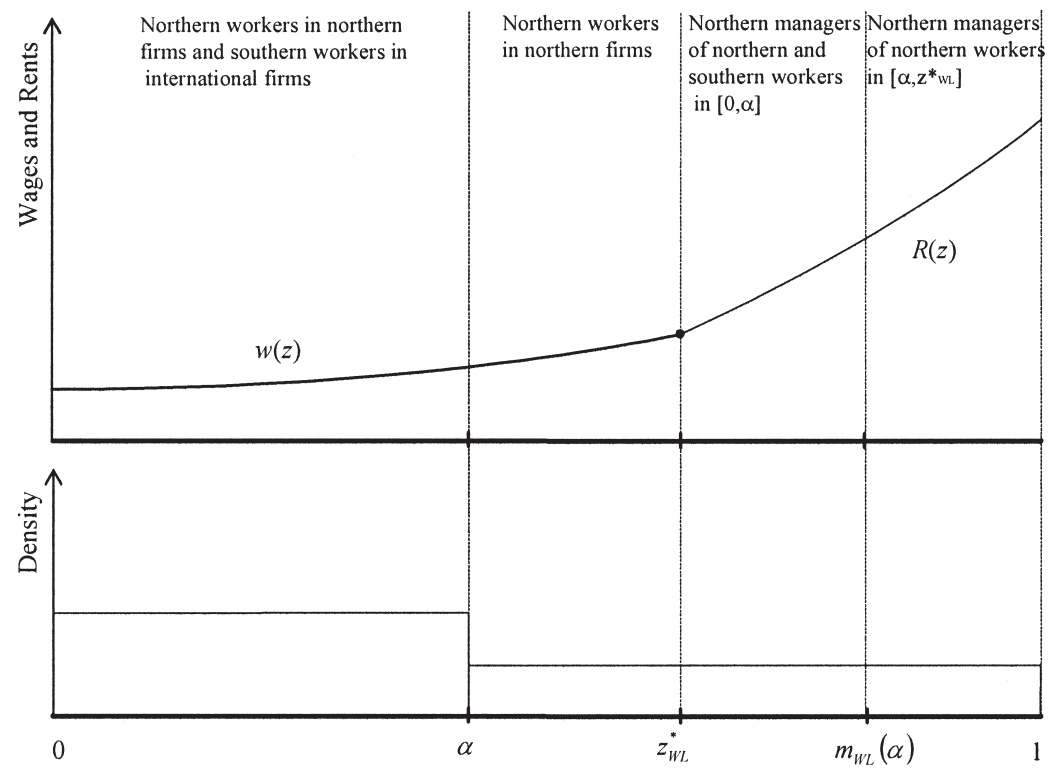

Figure II

Low Quality Offshoring Equilibrium

that divides occupations, in a $\mathrm{HQE}$ it must be the case that $z_{W H}^{*}<$ $\alpha$. Positive sorting implies that, since managers in the South are some of the lowest skill managers in the world, they are matched with the lowest skilled agents. In particular, they are matched with agents in the set $\left[0, z_{\alpha}\right]$, where the threshold $z_{\alpha}$ is defined by the worker type that works for the best agent in the South, namely, $m\left(z_{\alpha}\right)=\alpha$. Agents with skill lower than $z_{\alpha}$ work for managers in their own country (since we focus on the equilibrium with the least amount of offshoring), and workers with skill greater than $z_{\alpha}$ work in international teams. Then, labor market clearing implies that

$$
m_{W H}^{\prime}(z)= \begin{cases}h(1-z) & \text { if } 0<z<z_{\alpha} \\ ((1+\alpha) / \alpha) h(1-z) & \text { if } z_{\alpha}<z<z_{W H}^{*},\end{cases}
$$

which restates condition (3) for this case, together with the same boundary conditions as in the LQE: $m(0)=z_{W H}^{*}$ and $m\left(z_{W H}^{*}\right)=$ 1. On top of this we have to guarantee again that the equilibrium assignment function is continuous, in particular at $z_{\alpha}$, in order for the wage function to be differentiable. These conditions then result in an equilibrium assignment function given by 


$$
m_{W H}(z)= \begin{cases}z_{W H}^{*}+h z(1-1 / 2 z) & \text { if } 0<z<z_{\alpha} \\ z_{W H}^{*}-(1 / \alpha) h z_{\alpha}\left(1-1 / 2 z_{\alpha}\right) & \\ +((1+\alpha) / \alpha) h z(1-1 / 2 z) & \text { if } z_{\alpha}<z<z_{W H}^{*}\end{cases}
$$

and a threshold

$$
z_{W H}^{*}=\frac{1+h-\sqrt{1+h^{2}+((1-\alpha) /(1+\alpha)) 2 h}}{h} .
$$

One can verify again that $z_{W H}^{*}$ is decreasing in $h$ and increasing in $\alpha$. Using the definition of $z_{\alpha}$, we also obtain that

$$
z_{\alpha}=1-\sqrt{1-2\left(\frac{\alpha-z_{W H}^{*}}{h}\right)}
$$

It is straightforward to show that the condition that ensures that this world equilibrium is a $\mathrm{HQE}$ (i.e., $z_{W}^{*}<\alpha$ ) is the reciprocal of condition (11).

Again, maximization of rents implies that condition (2) has to be satisfied, together with $w_{W H}\left(z_{W H}^{*}\right)=R_{W H}\left(z_{W H}^{*}\right)$ and continuity of wages at $z_{\alpha}$. Solving the two differential equations, we obtain that

$$
\begin{aligned}
& w_{W H}(z) \\
& = \begin{cases}z_{W H}^{*}-\sigma_{1 H}(1-z)+1 / 2 h z^{2} & \text { if } 0<z<z_{\alpha} \\
z_{W H}^{*}-(1 / \alpha) h z_{\alpha}\left(1-1 / 2 z_{\alpha}\right)-\sigma_{2 H}(1-z) & \\
+1 / 2((1+\alpha) / \alpha) h z^{2} & \text { if } z_{\alpha}<z<z_{W H}^{*}\end{cases}
\end{aligned}
$$

where

$$
\sigma_{1 H}=\frac{h z_{W H}^{*}\left(1-(1 / \alpha) h z_{\alpha}+((1+\alpha) / 2 \alpha) h z_{W H}^{*}\right)+(1 / 2 \alpha)\left(h z_{\alpha}\right)^{2}}{1+h-h z_{W H}^{*}}
$$

and

$$
\sigma_{2 H}=\sigma_{1 H}-(h / \alpha) z_{\alpha} .
$$

As in the LQE, it is easy to show that the marginal return to skill is increasing in the level of skill and is larger for managers than for workers.

Let us summarize what we have shown for the HQE using Figure III. Agents with skill in $\left[0, z_{\alpha}\right]$ work in national firms for managers with skill in $\left[z_{W H}^{*}, \alpha\right]$. Agents with skill between $z_{\alpha}=$ 


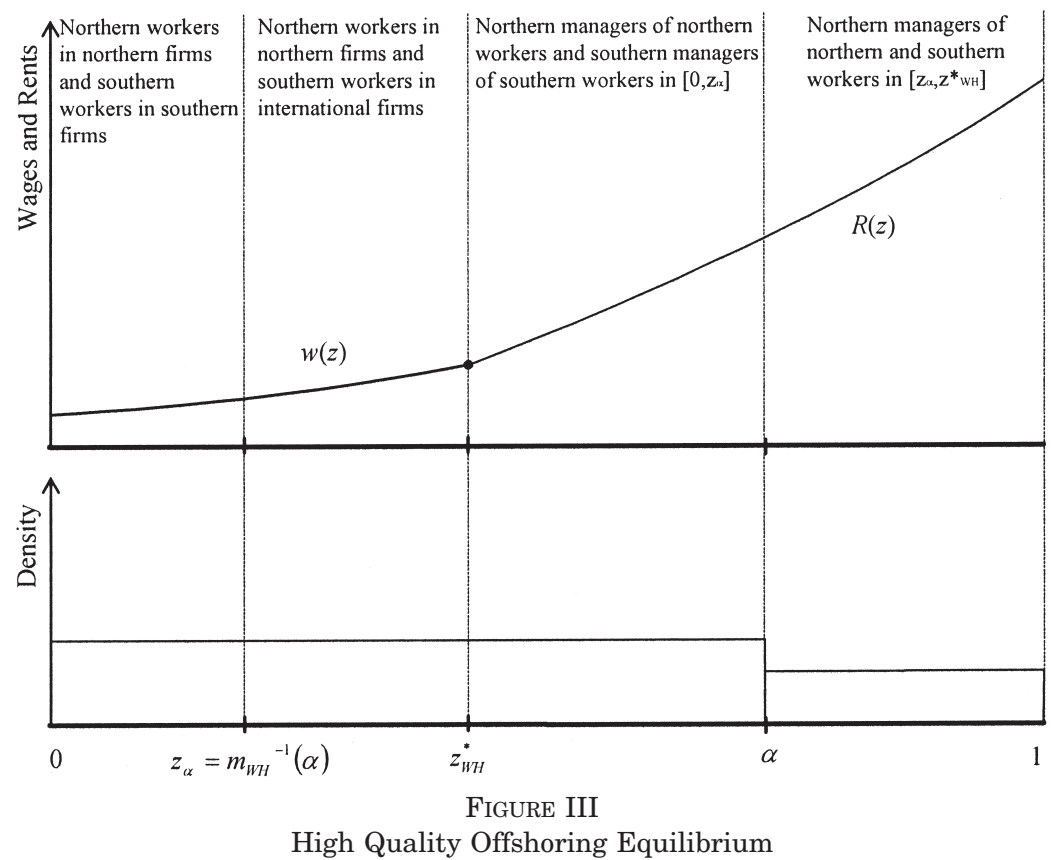

$m^{-1}(\alpha)$ and $z_{W H}^{*}$ work for northern managers with skill in [ $\left.\alpha, 1\right]$. This set of managers includes the ones that manage international teams. As before, the earnings function is continuous and differentiable everywhere except for $z_{W H}^{*}$ in which its slope increases discreetly.

\section{Effects of Globalization}

We study here the impact of an exogenous policy or technological change, that we call globalization, and that allows for the formation of international teams. We analyze its effects on the composition of teams, occupational choices, and the rewards structure of the economy. To do so, we compare the world equilibrium of Section III with the autarkic equilibria in the North and South that we described in Section II.

IV.A. Matching, Occupational Choice, and Firm Characteristics

To compare the open and autarkic equilibria, we use Figure IV. The figure presents the matching functions in autarky and 


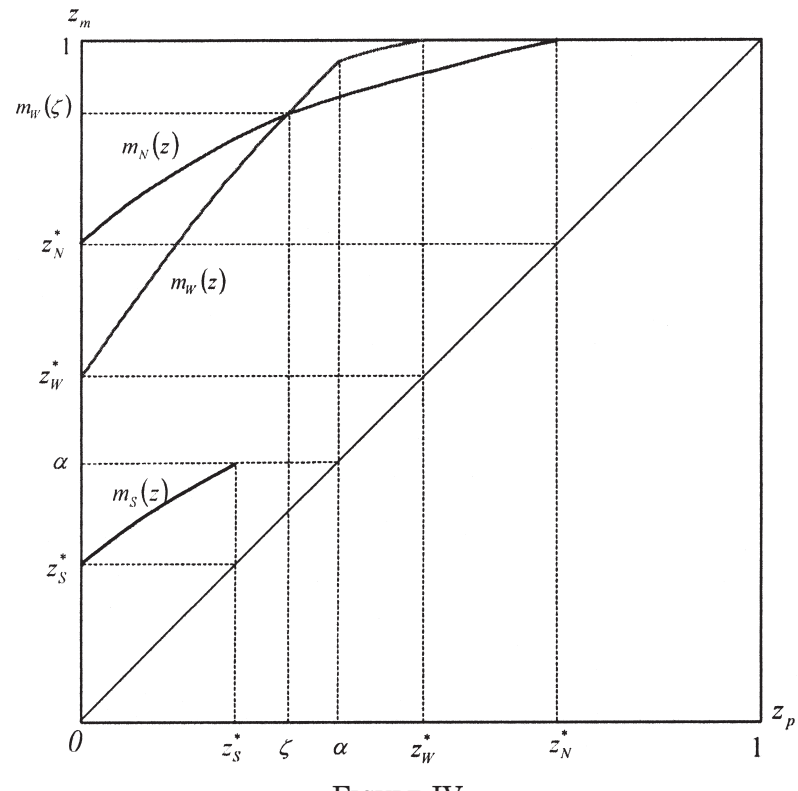

Figure IVa

Matching before $\left(m_{N}(z), m_{S}(z)\right)$ and after $\left(m_{W}(z)\right)$ globalization in a LQE

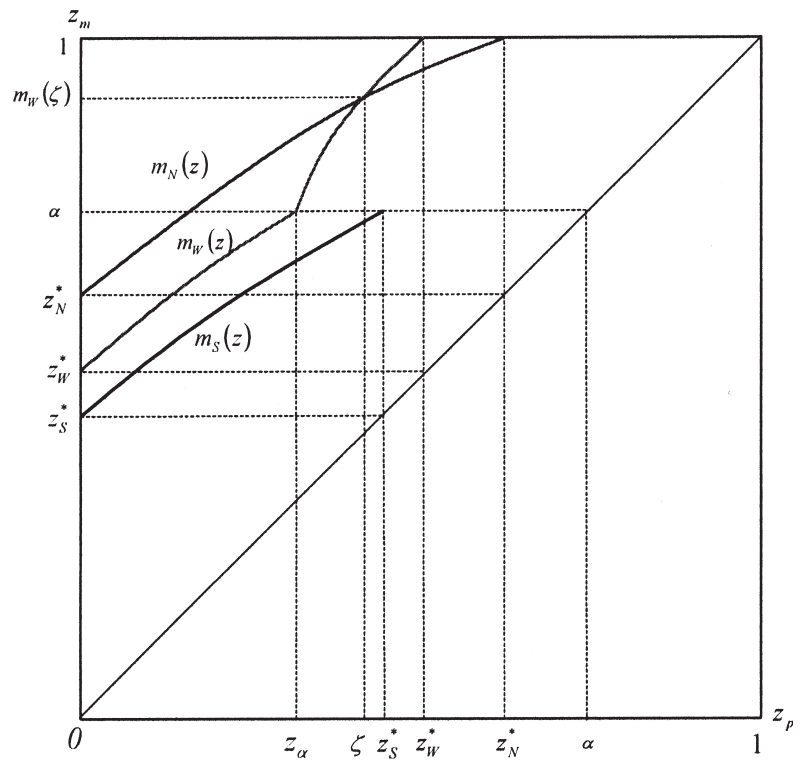

FiguRe IVb

Matching before $\left(m_{N}(z), m_{S}(z)\right)$ and after $\left(m_{W}(z)\right)$ globalization in a HQE 
the two types of world equilibria. The blending of the two skill distributions produces a rearrangement of the matches for both northern and southern workers. Independently of the equilibrium we are studying, all workers in the South strictly improve their match. This is the case even for southern workers who do not match with international managers, since some southern managers become workers in international teams, and the absence of these managers increases the quality of the match of every worker. Agents who were managers before globalization may either become workers (as there is a supply of higher quality managers who can do their problem solving job better) or remain as managers. In the latter case, they are matched with lower skill workers, precisely because some of the southern managers who were previously managing low quality workers have become workers, and the remaining managers are left to hire lower quality agents. In other words, while workers always benefit from the higher quality managers available for matching, managers' matches suffer from the increasing competition of better international managers.

The picture is considerably different for workers in the North. The key change is in the opportunities of the middleskilled agents in the North. Previously, they were not "good enough" to be team managers. After globalization, there is a set of low-skilled agents who need managing. As a result, some of these marginal workers become managers of low skilled agents. This implies that matches of northern agents with sufficiently low skill necessarily become worse. However, the highly skilled workers in the North now have less competition, since some of their highly skilled competitors, particularly the ones who were previously matched with the best northern managers, have become managers. Hence, as we show formally in Proposition 1 and illustrate in Figure IV, there is a skill level $\zeta$ below which workers have worse matches, while above it northern workers improve their matches. The following proposition formalizes these results. ${ }^{20}$ PRoposition 1. Globalization has the following effects on team
formation:

20. When the distinction between LQE and HQE is not relevant, we denote variables in the world economy with a subscript $W$. We follow this notation for all variables and functions. 
(i) The mass of southern workers and the mass of northern managers both increase, i.e., $z_{S}^{*}<z_{W}^{*}<z_{N}^{*}$;

(ii) (a) Southern workers who were already workers are matched with a better manager;

(b) Southern managers who remain managers are matched with worse workers;

(c) Southern managers who become workers are matched with a northern manager;

(iii) (a) There exists a unique threshold $\zeta$ such that all northern workers who remain workers with $z<\zeta$ are matched with a worse manager, while those with $z>\zeta$ are matched with a better manager;

(b) All northern managers who were already managers with $z<m_{W}(\zeta)$ are matched with a better worker, while those with $z>m_{W}(\zeta)$ are matched with a worse worker.

Part (i) of Proposition 1 implies that globalization leads to the creation of routine (worker) jobs in the South and to their destruction in the North. Similarly, if firms are identified by the managers who run them, we can conclude that globalization leads to firm destruction in the South and to firm creation in the North. Parts (ii) and (iii) in turn imply that the size of the largest firms in the North decreases, while some other firms will become larger, since some managers in the North improve their match. In contrast, all businesses based in the South that remain alive shrink. This leads to the following corollary.

Corollary 1. Globalization leads to routine job creation and firm destruction in the South, and to routine job destruction and firm creation in the North. Furthermore, it compresses the support of the size distribution of firms in both countries and reduces the size of all surviving southern firms.

Proposition 1 also implies that the best workers in the South are in international teams and thus work for the most productive and larger firms doing business in the South. This sorting may provide a rationale for the often-found evidence that "southern" workers employed in multinational firms receive wages that are on average higher than those received by workers employed in domestic firms (see, for instance, Aitken, Harrison, and Lipsey [1996] and Lipsey and Sjoholm [2004]). More specifically, a rationale for the regression result is simply that those who hold 
offshored jobs are unobservably more skilled than those who do not, and so they are matched with better managers. ${ }^{21}$ In sum,

CoRollary 2. The best workers in the South work for northern managers and receive higher wages than southern workers who are employed by southern managers.

\section{IV.B. Wage Inequality, Returns to Skill, and Wage Levels}

The previous subsection focused on the implications of our theory for quantities. Corresponding to those quantities there are equilibrium effects of globalization on prices. That is, workers' wages and managerial earnings must be such that matches are rearranged in the way we have described.

We first need to propose a set of measures that will help us characterize the effect of globalization on the distribution of wages, and in particular wage inequality. One potential measure of wage inequality is the ratio of the wage of the highest skilled agent and the wage of the lowest skilled agent (e.g., $w\left(z_{W}^{*}\right) / w(0)$ ). The problem with this measure is that it combines the level and slope effects on the wage distribution in a way that is not always straightforward to disentangle. To avoid this problem, we focus on changes in the absolute difference between the wage of the highest skill workers and that of the lowest skilled ones. That is, $w_{W}\left(z_{W}^{*}\right)-w_{W}(0)$. We will use this measure consistently every time we talk about wage inequality.

An alternative measure of changes in wage inequality in the context of our model is the change in the nonlinear (quadratic) term in the wage equation. This term, which we refer to as the complementarity effect, measures the premium that a worker receives for possessing a particular skill level, in excess of what several separate workers would receive for possessing the same aggregate amount of skill. In other words, the term reflects the extent to which workers with different skill levels are imperfect substitutes in production.

These two measures directly relate changes in wages to changes in matching. Our preferred interpretation of the empiri-

21. Controlling linearly for the skill of workers is unlikely to solve this problem, as earnings are the result, as we showed above, of the interaction between the skill of the worker and that of the (higher quality) international manager. In particular, Aitken, Hanson, and Harrison [1996] only distinguish between skilled and unskilled workers, and Lipsey and Sjoholm [2004] control linearly for educational attainment of workers. None of these controls eliminates the relationship between wages and multinationals generated by our framework. 
cal evidence concerning wage inequality in the South (e.g., Feenstra and Hanson [1997] and Hanson and Harrison [1999]) maps this evidence to changes in within-worker wage inequality in our model, since all blue-collar (unskilled) workers, but also some white-collar (skilled) workers, should be considered workers and not managers in our theory. ${ }^{22}$ Of course, some white-collar workers would probably be considered managers. Still, given the empirical definitions of occupations, we believe that the best way to interpret a high-skill-low-skill wage gap in our model is as the gap between the wages of the most and least skilled workers, which is our measure of wage inequality. We discuss, for completeness, the impact of globalization on some overall measures of inequality at the end of this section. ${ }^{23}$

The analysis of the impact of globalization on inequality follows quite directly from the changes in matching. First, inequality within southern workers unambiguously increases. The marginal value of workers' skill is driven by the skill of the manager with whom they are matched, which increases for all southern workers. Thus, the sum of the complementarity and the competition effects unambiguously leads to higher returns to skill in this case. Moreover, measured within-worker inequality will increase even more, since the mass of workers in the South unambiguously increases (occupational choice effect).

Proposition 2. Globalization increases within-worker wage inequality in the South. Furthermore, it increases the marginal return to skill for southern workers at all skill levels.

Consider next the effects of globalization on northern wage inequality. Globalization decreases the quality of the match of those northern workers who are relatively unskilled and increases it for the more skilled among them. As we could expect, given that the marginal return to skill of all workers is a function of the quality of the match, the returns to skill for relatively low

22. Feenstra and Hanson [1997] and Hanson and Harrison [1999] define unskilled workers as blue-collar workers and skilled workers as white-collar workers. White-collar workers are in charge of tasks such as management, product development, administration, and general office tasks. The latter three tasks can be interpreted as worker tasks in our model. The occupational distinction in our theory is not between blue- or white-collar workers, but between low level, front-line, routine tasks (including white-collar tasks such as handling the calls at a call center, or processing the back office paper work for a bank) and specialized problem solving, dealing with exceptions, namely, managerial tasks.

23. To our knowledge, the effect of offshoring on these measures of overall income inequality has not been studied in the empirical literature. 
skilled northern workers go down, and the returns to skill for the more skilled ones go up. The equilibrium effect on the marginal return to skill can again be decomposed in two. First, because now there is more competition from workers in the South, the baseline return per unit of skill always goes down $\left(\sigma_{1 W}-\sigma_{N}<\right.$ 0 ), as we can verify numerically for all parameter values. ${ }^{24}$

Second, since there are relatively more workers with low skill in the world than in the North, an increase in the skill level of workers increases the quality of their managers more after globalization. Thus, the complementarity effect tends to increase the marginal return to skill. This second effect is larger the higher the ability of the workers, since they are part of larger teams, as long as southern and northern workers compete for the same manager. In fact, for workers without skill, $z=0$, this effect is not present so the first effect has to dominate, and the marginal return to skill decreases. Numerically, we can show that the second effect dominates for workers with skill above a certain threshold, and so the marginal return to skill increases for them. The threshold ability at which both effects are identical is a function of the parameters $h$ and $\alpha$. The lower $\alpha$, the more southern agents are being added at each skill level where workers in both countries compete, and so the larger the set of abilities in which the complementarity effect dominates. The lower $h$, the smaller the competition effect, and so again the threshold of abilities decreases.

In order to understand the effects on wage inequality, we need to combine this reasoning with the occupational choice effect. In particular, the fact that after globalization fewer agents in the North become workers, which reduces wage disparity. Numerically, we can conclude that wage inequality in the North increases when $h$ and $\alpha$ are small, but decreases when these parameters are large. As mentioned in the introduction, this prediction is consistent with the findings of Feenstra and Hanson [1996b, 1999], who reported a significant positive effect of offshoring on U. S. wage inequality in the 1980s, but not in the 1970s. We summarize these results below.

24. In our two-parameter model it is straightforward to analyze numerically different equilibrium values for a tight grid of the whole parameter space. In the working paper version of the paper [Antràs, Garicano, and Rossi-Hansberg 2005], we provide graphical illustrations of all the numerical results discussed below. 
SUMmARY 1. Globalization increases within-worker wage inequality in the North if $h$ and $\alpha$ are sufficiently low, but it decreases it if $h$ and $\alpha$ are sufficiently high. Furthermore, globalization decreases the marginal return to skill of all northern workers with knowledge $z$ below a threshold, but increases the marginal return to skill of all northern workers above this threshold.

We are also interested in studying the effect of globalization on the level of wages, which is the result of two effects: on one hand, southern workers face more competition from low skill northern workers; on the other hand, globalization improves their match. In contrast, in the North, workers also face more competition, but they do not always improve their match (as described in Proposition 1). If we focus attention on the effect of globalization on the lowest skilled agents (for which the match deteriorates in the North), we can show numerically the following results.

Summary 2. Globalization has the following effects on wages:

(i) Increases the wages of low skilled southern workers for low $h$ and $\alpha$, but decreases them for high $h$ and $\alpha$;

(ii) Decreases the wages of low skilled northern workers for low $h$ and $\alpha$, but increases them for high $h$ and $\alpha$;

(iii) It decreases the wage of at least some low skilled agents.

Our model also allows us to derive some conclusions on wage inequality among managers in both countries. In particular, remember that the marginal return to skill of managers is given by the size of their team. From Proposition 1 we know that all managers in the South will have smaller teams and so the marginal return to skill for them decreases. Since there are also fewer of them, within-manager income inequality in the South decreases. In the North, there are two opposing forces. First, from Proposition 1 we know that the lowest skill managers, who were in managerial positions before globalization, will have larger teams, but the best managers will have smaller teams. This implies that the return to skill of low ability managers increases and that of high ability managers decreases. Second, there are more managers in the North, so the occupational choice effect leads to more income inequality among managers. This reasoning leads to the following corollary of Proposition 1. 
CoRollary 3. Globalization has the following effects on withinmanager income inequality and on the marginal return to skill of managers:

(i) Globalization decreases within-manager income inequality and the marginal return to skill of all southern managers;

(ii) Globalization increases the marginal return to skill for northern managers with knowledge $z$ below a threshold but decreases it for the rest.

We now turn to analyze the predictions of the model for other measures of inequality. The changes in within-worker inequality in the North, together with compositional changes, suggest that inequality is more likely to increase at the top of the northern skill distribution than at the bottom. Intuitively, some northern workers improve their matches, but some others suffer from southern competition and get worse matches-thus, the increase in within-worker inequality is moderate. However, globalization increases the share of northern agents who are managers, and inequality within managers is always large, since managers are able to leverage their skill over an entire team. Indeed, we find numerically that inequality in the North, as given by the gap between the earnings of the ninetieth percentile agent and those of the fiftieth percentile agent (the 90/50 gap) increases for all $h$ and for all $\alpha$. In contrast, the 50/10 gap may or not increase. We also find numerically that the expected increase in the 90/50 gap, where the expectation taken over all $h$ and $\alpha$ (assuming uniform distributions for both parameters) is larger than the expected increase in the 50/10 gap. Both of these findings suggest that offshoring may provide an explanation for the empirical finding (see Murphy and Welch [2001] or Autor, Katz, and Kearney [2004]) that wage inequality in the United States has stabilized at the bottom of the distribution, but continues to grow at the top. ${ }^{25}$

The fact that the model allows us to characterize the whole earnings distribution suggests that we can compute any measure of inequality, and for instance we can study the effect of offshor-

25. Autor, Levy, and Murnane [2003] develop a model that differentiates between routine and nonroutine tasks, where only the aggregate units of factors enter the production function. Such a model could also potentially be applied to study offshoring, but would miss the effect of offshoring on matching, and therefore, within-group wage inequality, that is central in our analysis. 
ing on overall inequality. Finding robust results for these measures is unlikely since wage levels will be affected by the relative masses of agents at each point of the distribution, and we have shown analytically that offshoring leads to contradictory effects on inequality within managers and within workers. We compute the expected changes in overall inequality that globalization brings about when the South is relatively unskilled (expectations are taken over $\alpha<0.5$ and $h$ ). In the North, globalization leads to an increase in the standard deviation of income (wages and rents), in the 90/10 gap, and in the manager/worker gap (as measured by the difference between the mean managerial rent and the mean worker wage). In the South, globalization implies an increase in the standard deviation of income and in the manager worker gap, but a drop in the 90/10 gap. The reason that these measures differ in the South is that, for a given wage function, the first one takes into account the relative mass of workers to managers, while the last one does not. ${ }^{26}$

\section{IV.C. Production, Consumption, and Trade}

As argued above, Theorem 1 applies also to the equilibrium of the world economy, and therefore the equilibrium is unique and efficient. As a result, since in the world economy we could always replicate the equilibrium in the closed economies of the North and the South, we know that in our framework there are always welfare gains from international offshoring. The following corollary summarizes this conclusion.

CoROLLARY 4. Globalization increases total production in the world economy. That is, there are gains from trade.

How are these gains distributed between the countries? Define a country's physical output as the quantity of goods that are produced by its workers, since they are the ones who combine labor and knowledge to produce. In the South, Proposition 1 implies that there are more and better matched workers and so total physical output increases. In the North there are fewer workers, and some of them have worse matches. We can show numerically that, for all combinations of $h$ and $\alpha$, physical production decreases in the North. Hence, in terms of physical value

26. We find that, when the South is relatively skilled $(\alpha>0.5)$, the same changes take place in the North and the South, except that the manager/worker gap decreases in the South. 
added, the "winner" of globalization is the South. The reason why the North produces less after globalization is that physical production does not take into account that managers' rents have to be repatriated. Managers consume in their own country, and they receive-as compensation for the time spent helping and communicating with workers abroad-part of the production of these workers. These rents can be substantial and in fact imply that consumption in both countries increases and, since utility is linear, so does welfare.

This difference in consumption and production outcomes is reflected in the trade balance of these countries. In particular, the South features net exports of physical goods, while the North features net exports of knowledge services. ${ }^{27}$ Furthermore, if knowledge transactions are not registered as imports for the South and exports for the North, the trade balance of the northern country will be in deficit and that of the southern country in surplus. This deficit and surplus is, however, not evidence of an imbalance, but just the result of the potential misrecording of knowledge transactions. This reasoning suggests that some of these forces may be at play when we look at the trade balance of the United States with some of its Asian trade partners, like China. ${ }^{28}$ We summarize these conclusions below.

Summary 3. Globalization has the following effects on physical production, consumption, and the trade balance:

(i) It increases physical production in the South and decreases physical production in the North;

(ii) It increases consumption (and thus welfare) in both countries;

(iii) The pattern of trade is such that the South exports manufactures and the North exports knowledge services;

(iv) If knowledge transactions are not reported, globalization generates a trade surplus in the South and a trade deficit in the North.

27. Indeed, using $m_{W}(z)>w(z)$, it is straightforward to show that $Y_{W S}-$ $C_{W S}>0$, which of course implies that $Y_{W N}-C_{W N}<0$.

28. Note that this misrecording will not be evident in the capital account as long as some of the manager's rents are kept offshore. 


\section{IV.D. Generalizations}

Our setup has assumed particular functional forms for the distributions of ability. We now briefly outline the robustness of some key results to more general distributions. First, we can show that for globalization to lead to the creation of routine jobs in the South and to their destruction in the North (i.e., $z_{S}^{*}<z_{W}^{*}<$ $z_{N}^{*}$ ) all that is required is that the distribution of ability in the North first-order stochastically dominates that in the South (i.e., $G_{N}(z)<G_{S}(z)$ for all $\left.z\right)$.

Second, we note that the complementarity effect (which is novel in our setup) is generally given by the expression,

$$
w^{\prime \prime}(z)=h \frac{g(z)}{g(m(z))}=\frac{m^{\prime}(z)}{1-z},
$$

which highlights the close relationship between matching and wage inequality in our setup. ${ }^{29}$ Furthermore, if in addition to first-order stochastic dominance we assume that the distributions of ability in the South and the world satisfy

$$
\frac{g_{S}(z)}{g_{S}\left(z^{\prime}\right)} \leq \frac{g_{W}(z)}{g_{W}\left(z^{\prime \prime}\right)} \quad \text { for } \quad z<z^{\prime}<z^{\prime \prime},
$$

then we can show that $m_{W}(z) \geq m_{S}(z)$ and $w_{W}^{\prime \prime}(z) \geq w_{S}^{\prime \prime}(z)$ for all $z<z_{S}^{*}$. These conditions ensure that, from the point of view of the South, globalization improves the match of all southern workers (with the implications for the size distribution of firms noted in subsection IV.A) and leads to an increase in wage inequality on account of the complementarity effect.

Note that these conditions are only sufficient not necessary, and that they guarantee improved matches and a larger complementarity effect for all ability levels in the South. If any of these assumptions on the distributions does not hold, it may be the case that the complementarity effect decreases with integration in the South. To illustrate this, consider the case where the distributions in the North and South are both uniform, but the range of

29. This characterization of the complementarity effect allows us to derive conclusions on the wage effects of changes in population size. Consider our setup with overlapping uniform distributions of ability. Suppose, for example, that population size in the South increases, keeping the support of the distribution of abilities constant, but increasing the density by the same amount for all ability levels. Then it is straightforward to see that the ratio $g_{W}(z) / g_{W}\left(m_{W}(z)\right)$ will weakly increase, while $g_{i}(z) / g_{i}\left(m_{i}(z)\right)$ will be unaffected for $i=N, S$. Thus, the larger the population size in the South, the larger the increase that globalization will cause, through the complementarity effect, on wage inequality. 
abilities in the South is given by $[0,1]$ and in the North by $[\beta, 1]$, so condition (19) is not satisfied. In this case there exists a $\beta$ such that for some $z \in\left[0, z_{S}^{*}\right]$,

$$
w_{W}^{\prime \prime}(z)=h \frac{g_{W}(z)}{g_{W}\left(m_{W}(z)\right)}=h \frac{1}{1+\beta}<h=w_{S}^{\prime \prime}(z) .
$$

That is, integration may lead to a decrease in the complementarity effect. Note, however, that in the above example it is still the case that $G_{N}(z)<G_{S}(z)$ for all $z$, and thus the patterns of specialization in the global economy are analogous to those discussed in our benchmark case.

\section{Comparative Statics in the World Economy}

In this section we analyze the effect of changes in communication costs $(h)$ and the skill overlap $(\alpha)$ on the equilibrium outcome of the integrated economy. For brevity we only report the impact of these changes on occupational choices, characteristics (quantity and quality) of international offshoring, and matching. We also discuss briefly some implications of these changes for the structure of earnings in the world economy. More details on these comparative statics are provided in Antràs, Garicano, and RossiHansberg [2005].

Occupational Choice. As $h$ decreases, managers have access to a communication technology that allows them to deal with larger teams. As a result, the number of workers in the South weakly decreases with $h$, and the number of workers in the North decreases with $h$. The number of managers in the South in turn weakly increases with $h$, and the number of managers in the North increases with $h$. As $\alpha$ increases, agents in the South become relatively more skilled. This implies that the number of workers in the South weakly decreases with $\alpha$, whereas the number of workers in the North increases. In contrast, the number of managers in the South weakly increases with $\alpha$, whereas the number of managers in the North decreases with $\alpha$. These conclusions are implied by the following proposition.

Proposition 3. The skill of the world's most-skilled worker $\left(z_{W}^{*}\right)$ is decreasing in communication costs $(h)$ and increasing in the skill overlap $(\alpha)$. 
The Quantity and Quality of Offshoring. To analyze the quantity of offshoring, we need a measure that captures the extent to which firms in the economy are formed by national versus international teams. Therefore, we define the quantity of offshoring as the proportion of southern workers that work for international teams. In a LQE, all agents in the South are workers in international teams, so it follows that our measure of offshoring equals one. In contrast, in a $\mathrm{HQE}$, the quantity of offshoring is given by

$$
O_{W} \equiv\left(z_{W H}^{*}-z_{\alpha}\right) / z_{W H}^{*} .
$$

The proportion of workers in international teams is always less than one in a $\mathrm{HQE}$, but converges to one as we change parameters to approach the boundary between both type of equilibria. Hence, in a LQE there is always more offshoring than in a HQE.

We also want to derive conclusions on the characteristics of the firms that engage in offshoring. For this purpose, we define the quality of offshoring as the average skill level of the workers that form international teams relative to the skill level of all southern workers,

$$
Q_{W} \equiv\left(z_{W H}^{*}+z_{\alpha}\right) / z_{W H}^{*} .
$$

In a $\mathrm{HQE}$ the quality of offshoring is always larger than one and again converges to one as we change parameter values in a way that approaches the boundary between equilibria. Clearly, $O_{W}=$ $2-Q_{W}$, and so the same forces that cause an increase in offshoring will simultaneously reduce its quality. With these measures at hand, we derive the next result.

Proposition 4. The quantity of international offshoring is weakly decreasing in communication costs $(h)$ and the skill overlap $(\alpha)$. Furthermore, the quality of offshoring is weakly increasing in $h$ and $\alpha$.

Matching and Firm Characteristics. A fall in $h$ improves the skill level of the worst manager and so improves the match of the worst workers, $z=0$. Conversely, the best worker before the fall in $h$ is now matched with a worse manager. Moreover, we can show that the direct effect of the technological improvement on firm size dominates these effects, thereby leading to an increase in the size of all firms in the economy. In contrast, changes in $\alpha$ have distinct effects on small versus large firms. As $\alpha$ increases, workers with low skill levels will be matched with better manag- 
ers, and will thus work for more productive firms. Workers with high skill levels will be matched with worse managers and so the productivity of the firms for which they work will decrease. We formalize these conclusions in the next proposition.

Proposition 5. A decrease in communication costs $(h)$ has the following effects on matching and firm size:

(i) It improves the match for workers below a threshold skill level $\varphi$, while it worsens the match for workers (who were already workers) above $\varphi$;

(ii) It increases the size of all firms.

An increase in the skill overlap $(\alpha)$ has the following effects on matching and firm size:

(i) It improves the match for workers below a threshold skill level, while it worsens the match for workers with skill above this threshold;

(ii) It increases the size of the largest firms and decreases the size of the smallest firms;

(iii) It increases the size of the largest offshorers and decreases the size of the smallest offshorers;

(iv) It increases the size of all nonoffshorers in a LQE, but decreases the size of all nonoffshorers in a HQE.

Managerial Rents and Wages. Concerning managerial rents, a decrease in $h$ increases the marginal return to skill for managers, since all firms grow and the marginal return to skill of managers is equal to firm size. The effect of $\alpha$ on firm size is not the same for all firms. We can, however, conclude that the marginal return to skill of the worst managers decreases and the marginal return to skill of the best managers increases.

Now consider the effect of changes in $h$ and $\alpha$ on the wage structure. First, the complementarity effect (the quadratic term in both (12) and (17)) increases with $h$, and weakly decreases with $\alpha$. The reason is that as $h$ increases, team sizes decrease, and so having more skill will imply matching with a much better manager. In contrast, an increase in $\alpha$ leads to a decrease in density for all skill levels in the South (and thus for the levels in which northern and southern workers compete). Hence, a slightly better worker will now match with only a slightly better manager. Second, $h$ has an ambiguous effect, and $\alpha$ increases the competition effect, as measured by the baseline unit of skill $\left(\sigma_{1 L}\right.$ and $\left.\sigma_{1 H}\right)$. The latter effect follows from $\alpha$ increasing workers' skills in 
a LQE and making them more scarce in a HQE. Third, as shown in Proposition 3, the occupational choice effect decreases with $h$ and increases with $\alpha$, since the set of workers increases and shrinks, respectively. ${ }^{30}$

\section{Conclusions}

We have developed a theory of offshoring in which agents with heterogeneous abilities sort into teams competitively. We have analyzed the effects of globalization on the organization of work, the size distribution of firms, and the structure of earnings of individuals, and we have illustrated how these outcomes in turn determine the patterns of production, consumption, and international trade in the global economy.

We have shown that the effects of globalization interact in nontrivial ways with the state of communication technologies. For example, in our model globalization always increases withinworker wage inequality in the South, but it increases withinworker inequality in the North only if the costs of communicating knowledge are relatively low. Similarly, we have shown that the characteristics of international offshoring also depend very much on the state of communication technologies: the lower are communication costs, the higher is the amount of international offshoring, but the lower is its quality.

In order to highlight the main forces in the model, our theoretical framework has abstracted from certain aspects that are central in shaping the international organization of production. First, we have imposed that production is undertaken by twolayer teams consisting of a manager and a set of workers. It would be interesting to incorporate the possibility of both self-employment and multiple layers in our model. This would open the door for a study of how globalization affects the incentives to offshore or not to different countries, as well as the way it affects the hierarchical structure of firms. Second, we have presented a purely technological theory of the international organization of production. A caveat of this approach is that we can explain why

30. The overall effect of $h$ and $\alpha$ on wage inequality results from the combination of these three effects. In Antràs, Garicano, and Rossi-Hansberg [2005] we show, for instance, that our model is consistent with an increase in the relative endowment of skilled agents in the South $(a$ higher $\alpha$ ) leading to increased within-worker inequality in that country. This is consistent with the findings of Zhu and Trefler [2005] and is not easily rationalizable with standard general equilibrium models. 
a northern manager might have an incentive to form a team with a group of southern workers, but we have less to say about why this international exchange of knowledge will occur within firm boundaries (i.e., within multinationals), rather than through arm's length subcontracting or licensing. It would be interesting to incorporate contractual frictions in our setup in order to obtain a more well-defined trade-off between in-house versus arm'slength offshoring. ${ }^{31}$

\section{APPENDIX}

Proof of Theorem 1. We first show that an equilibrium of this economy exhibits positive sorting. Let $\Pi\left(z_{m}, z_{p}\right)$ denote the rents of a manager of ability $z_{m}$ and hires workers with ability $z_{p}$. From our definitions above, we know that $\Pi(m(z), z)=R(m(z))$ if $m(\cdot)$ is the equilibrium assignment function. In equilibrium we know that managers choose the ability of their workers optimally so

$$
\frac{\partial \Pi\left(z_{m}, z_{p}\right)}{\partial z_{p}}=0 .
$$

Totally differentiating this expression, we obtain that

$$
\frac{\partial z_{m}}{\partial z_{p}}=-\frac{\partial^{2} \Pi\left(z_{m}, z_{p}\right) / \partial z_{p}^{2}}{\partial^{2} \Pi\left(z_{m}, z_{p}\right) / \partial z_{p} \partial z_{m}} .
$$

The numerator has to be negative since managers are maximizing rents in equilibrium. To show that the denominator is positive, notice that

$$
\frac{\partial^{2} \Pi\left(z_{m}, z_{p}\right)}{\partial z_{p} \partial z_{m}}=\frac{\partial\left(1 / h\left(1-z_{p}\right)\right)}{\partial z_{p}}=\frac{1}{h\left(1-z_{p}\right)^{2}}>0 .
$$

Hence,

$$
\frac{\partial z_{m}}{\partial z_{p}}>0 .
$$

Since the argument is valid for all workers, we conclude that in an equilibrium allocation $m^{\prime}(z)>0$ for all workers with ability $z$.

31. In a similar vein, Antràs [2003, 2005] and Antràs and Helpman [2004] embed the property-rights approach of Grossman and Hart [1986] in standard trade models. Grossman and Helpman [2004] in turn develop a model of the international organization of production that shares certain features with the multitask approach of Holmstrom and Milgrom [1994]. 
Let $w(\cdot)$ be an equilibrium wage function, and let $W(w)$ and $M(w)$ be the equilibrium set of agents who become workers and managers, respectively. Let $m(z)$ be the skill level of the manager of a worker with ability $z$, then

$$
h \int_{W \cap\left[0, z_{p}\right]}(1-z) g(z) d z=\int_{M \cap\left[m(0), m\left(z_{p}\right)\right]} g(z) d z \text { all } z_{p} \in W .
$$

Deriving with respect to $z_{p}$, we obtain that, as long as $z_{p}$ is in the interior of $W$ and $m(z)$ is increasing, as we showed above,

$$
m^{\prime}\left(z_{p}\right)=h\left(1-z_{p}\right) \frac{g\left(z_{p}\right)}{g\left(m\left(z_{p}\right)\right)} .
$$

We want to prove that an equilibrium in this economy implies that $W(w)$ is a connected interval. Suppose that it is not. In particular, suppose that $W=\left[a_{1}, a_{2}\right] \cup\left[a_{3}, a_{4}\right]$ and $M=\left[a_{2}, a_{3}\right] \cup$ $\left[a_{4}, a_{5}\right]$. Then, given $a_{1}$ and $a_{3}$, we know that $m\left(a_{1}\right)=a_{2}$ and $m\left(a_{2}\right)=a_{3}$. Combining these conditions with the differential equation for wages (and continuity of wages at $a_{2}$ ) and the expression above - that have to hold in the interior of $W$-we can solve for a wage function $w_{13}$, a rent function $R_{13}$ and a threshold $a_{2}$. Similarly, given $a_{3}$ and $a_{5}$, we can solve for a wage function $w_{35}$, a rent function $R_{35}$, and a threshold $a_{4}$ that satisfy all the equilibrium conditions in the interval $\left[a_{3}, a_{5}\right]$. In order for $W$ and $M$ to represent equilibrium occupational choices, we have to guarantee that agents in the interval $\left[a_{3}, a_{5}\right]$ do not want to form teams with agents in the interval $\left[a_{1}, a_{3}\right]$. The first necessary condition is that

$$
R_{13}\left(a_{3}\right)=w_{35}\left(a_{3}\right) .
$$

Since, if $R_{13}\left(a_{3}\right)>w_{35}\left(a_{3}\right)$, agents with skill above but arbitrarily close to $a_{3}$ would like to become managers. If $R_{13}\left(a_{3}\right)<$ $w_{35}\left(a_{3}\right)$, agents with skill marginally below $a_{3}$ would like to become workers, and agents at $a_{4}$ would like to hire them at a wage marginally larger than $R_{13}\left(a_{3}\right)$. The next condition is that

$$
\lim _{z \uparrow a_{3}} \frac{\partial R_{13}(z)}{\partial z}>\lim _{z \downarrow a_{3}} \frac{\partial w_{35}(z)}{\partial z} .
$$

To show that this is the case, notice that

$$
\frac{\partial R_{13}\left(a_{3}\right)}{\partial z}=\frac{1}{h\left(1-a_{2}\right)}>1
$$


by the envelope theorem. We will prove that the inequality above has to hold in equilibrium in two distinct cases: for the case when $w_{13}\left(a_{2}\right) \geq a_{2}$ and for the case when $w_{13}\left(a_{2}\right)<a_{2}$. Suppose that $w_{13}\left(a_{2}\right) \geq a_{2}$, then, since $\partial R_{13}(z) / \partial z>1$ for all $z \in\left[a_{2}, a_{3}\right]$, we know that $R_{13}\left(a_{3}\right)>a_{3}$ and since $R_{13}\left(a_{3}\right)=w_{35}\left(a_{3}\right), w_{35}\left(a_{3}\right)>$ $a_{3}$. Then since $h<1$ and $a_{2}<a_{3}<a_{4}<\bar{z} \leq 1$, we can conclude that

$$
\frac{\partial R_{13}\left(a_{3}\right)}{\partial z}=\frac{1}{h\left(1-a_{2}\right)}>1>\frac{a_{4}-w_{35}\left(a_{3}\right)}{1-a_{3}}=\frac{\partial w_{35}\left(a_{3}\right)}{\partial z},
$$

which proves condition (20) if $w_{13}\left(a_{2}\right) \geq a_{2}$. Now suppose that $w_{13}\left(a_{2}\right)<a_{2}$, then, since $w_{35}\left(a_{3}\right)=R_{13}\left(a_{3}\right)$, we can rewrite the right-hand side of the inequality as

$$
\frac{\partial w_{35}\left(a_{3}\right)}{\partial z}=\frac{a_{4}-w_{35}\left(a_{3}\right)}{1-a_{3}}=\frac{a_{4} h\left(1-a_{2}\right)-a_{3}+w_{13}\left(a_{2}\right)}{\left(1-a_{3}\right) h\left(1-a_{2}\right)} .
$$

Proving that condition (20) holds then amounts to prove that

$$
a_{4} h\left(1-a_{2}\right)+w_{13}\left(a_{2}\right)<1
$$

or

$$
a_{4}<\frac{1-w_{13}\left(a_{2}\right)}{h\left(1-a_{2}\right)} .
$$

But this is trivially satisfied given that $a_{4}<\bar{z} \leq 1$, and $w_{13}\left(a_{2}\right)<$ $a_{2}$.

We have established that condition (20) has to hold in equilibrium, but then $a_{4}$ would like to hire $a_{3}-\varepsilon$ at a better wage than what he makes as a manager, and $a_{3}-\varepsilon$ would accept the offer. To show this, consider the rents that $a_{4}$ would get from hiring $a_{3}-\varepsilon$ at wage $R_{13}\left(a_{3}-\varepsilon\right)$,

$$
\Pi\left(a_{4}, a_{3}-\varepsilon\right)=\frac{a_{4}-R_{13}\left(a_{3}-\varepsilon\right)}{h\left(1-\left(a_{3}-\varepsilon\right)\right)},
$$

and note that

$$
\lim _{\varepsilon \rightarrow 0} \frac{\partial \Pi\left(a_{4}, a_{3}-\varepsilon\right)}{\partial \varepsilon}=\frac{R_{13}^{\prime}\left(a_{3}\right)-w_{35}^{\prime}\left(a_{3}\right)}{h\left(1-a_{3}\right)}>0,
$$

where the inequality comes from the result above. Hence, an allocation where $W$ is not connected implies that there are incentives for agents to form different teams. This implies that an 
equilibrium requires that $W$ be a connected interval of the form $\left[0, z^{*}\right]$. Hence, in equilibrium $m(0)=z^{*}$, and $m\left(z^{*}\right)=\bar{z}$. An allocation that (i) satisfies the two differential equations above, (ii) satisfies the previous boundary conditions for assignment function $m$, and (iii) yields a continuous earnings function, exists and is unique (see Garicano and Rossi-Hansberg [2005]).

The final step is to prove that such an allocation is in fact an equilibrium. For this we need to prove that there exists an $h^{*}>$ 0 such that the allocation guaranteed to exist by the above reasoning is such that $R^{\prime}\left(z^{*}\right)>w^{\prime}\left(z^{*}\right)$. To show this, we use a similar argument to the one above. Consider the incentives of a manager with ability $\bar{z}$ to hire a worker with ability $z^{*}+\varepsilon$. Her profits are given by

$$
\Pi\left(\bar{z}, z^{*}+\varepsilon\right)=\frac{\bar{z}-R\left(z^{*}+\varepsilon\right)}{h\left(1-\left(z^{*}+\varepsilon\right)\right)}
$$

so

$$
\lim _{\varepsilon \rightarrow 0} \frac{\partial \Pi\left(\bar{z}, z^{*}+\varepsilon\right)}{\partial \varepsilon}=\frac{w\left(z^{*}\right)-R^{\prime}\left(z^{*}\right)}{h\left(1-z^{*}\right)},
$$

since $R\left(z^{*}\right)=w\left(z^{*}\right)$. Hence, in equilibrium it has to be the case that $R^{\prime}\left(z^{*}\right)>w^{\prime}\left(z^{*}\right)$ in order for this term to be negative. But notice that, since $R\left(z^{*}\right)=w\left(z^{*}\right)$,

$$
w^{\prime}\left(z^{*}\right)=\frac{\bar{z}-w\left(z^{*}\right)}{1-z^{*}}=\frac{h \bar{z}-z^{*}+w(0)}{\left(1-z^{*}\right) h},
$$

which is smaller than $1 / h$ if $h \bar{z}+w(0)<1$. Hence, since $w(0)<$ 1 (if not rents of all managers would be negative), this implies that there exists an $h^{*}>0$ such that for all $h<h^{*}$,

$$
w^{\prime}\left(z^{*}\right)<1 / h=R^{\prime}\left(z^{*}\right) .
$$

Hence, for all $h<h^{*}$, there exists a unique competitive equilibrium in this economy. Given that markets are complete and competitive, this implies that the equilibrium allocation in the economy is Pareto optimal.

To show that the earnings function is convex, first notice that from equation (3)

$$
w^{\prime \prime}\left(z_{p}\right)=h \frac{g\left(z_{p}\right)}{g\left(m\left(z_{p}\right)\right)}>0,
$$


while the rent function is such that

$$
R^{\prime \prime}\left(z_{m}\right)=\frac{\left(m^{-1}\right)^{\prime}\left(z_{m}\right)}{h\left(1-m^{-1}\left(z_{m}\right)\right)^{2}}>0,
$$

where the last inequality follows from positive sorting.

Proof of Proposition 1. (i) We first show that the mass of workers increases in the South. This is obviously the case in a LQE, because $z_{S}^{*}<\alpha<z_{W L}^{*} \cdot{ }^{32}$ On the other hand, for the case of a HQE, it suffices to show that $z_{S}^{*}<z_{W H}^{*}$, but this follows from simple inspection of the formulas for these thresholds. That the mass of workers decreases in the North follows from $z_{W H}^{*}<z_{N}^{*}$ and $z_{W L}^{*}<z_{N}^{*}$, which are both clearly true from the expressions for these thresholds.

(ii) For the first statement we want to show that both $m_{S}(z)<m_{W L}(z)$ and $m_{S}(z)<m_{W H}(z)$ for all $z \leq z_{S}^{*}$. The first inequality follows directly from $z_{W L}^{*}>z_{S}^{*}$ in a LQE. Similarly, $z_{W H}^{*}>z_{S}^{*}$ immediately implies that $m_{S}(z)<m_{W H}(z)$ for $z \leq z_{\alpha}$. For the interval $z_{\alpha}<z<z_{W H}^{*}$, it is useful to rewrite $m_{W H}(z)$ as $m_{W H}(z)=h z(1-1 / 2 z)+z_{W H}^{*}+(1 / \alpha) h\left[z(1-1 / 2 z)-z_{\alpha}(1-\right.$ $\left.1 / 2 z_{\alpha}\right)$ ]. The inequality then follows from $z_{W H}^{*}>z_{S}^{*}$ and the fact that $x(1-1 / 2 x)$ is nondecreasing in $x$ for $x \in[0,1]$. The second statement is an immediate corollary of this first result. For the third statement, it is sufficient to show that $m_{W H}\left(z_{S}^{*}\right)>\alpha$ for all $z_{S}^{*}<z<z_{W H}^{*}$. But notice that with a couple of substitutions, $m_{W H}\left(z_{S}^{*}\right)=\alpha+((1+\alpha) / \alpha)\left(z_{W H}^{*}-z_{S}^{*}\right)>\alpha$, and the result follows from the monotonicity of $m_{W H}(\cdot){ }^{33}$

(iii) To prove the first part, we simply write $m_{W}(z)-m_{N}(z)$ for each of the two equilibria. For the LQE one, this equals

$$
m_{W L}(z)-m_{N}(z)= \begin{cases}z_{W L}^{*}-z_{N}^{*}+(h / \alpha) z(1-1 / 2 z) & \text { if } 0<z<\alpha \\ z_{W L}^{*}-z_{N}^{*}+h(1-1 / 2 \alpha) & \text { if } \alpha<z<z_{W L}^{*},\end{cases}
$$

which is nondecreasing in $z$, is negative for low enough $z$ and is positive for high enough $z$ (notice that $z_{W L}^{*}-z_{N}^{*}+h(1-1 / 2 \alpha)>$ 0 is implied by $\left.m_{N}\left(z_{W L}^{*}\right)<1\right)$. For the HQE case, this equals

32. There are parameter values for which $z_{S}^{*}>z_{W L}^{*}$, but these are inconsistent with the existence of a LQE.

33. Notice that $m_{W H}\left(z_{S}^{*}\right)=h z_{S}^{*}\left(1-1 / 2 z_{S}^{*}\right)+z_{W H}^{*}+(1 / \alpha) h\left[z_{S}^{*}(1-\right.$ $\left.\left.1 / 2 z_{S}^{*}\right)-z_{\alpha}\left(1-1 / 2 z_{\alpha}\right)\right]$. The two substitutions are $h z_{S}^{*}\left(1-1 / 2 z_{S}^{*}\right)+z_{S}^{*}=\alpha$ and $h z_{\alpha}\left(1-1 / 2 z_{\alpha}\right)+z_{W H}^{* \alpha}=\alpha$. 


$$
\begin{aligned}
m_{W H}(z)- & m_{N}(z) \\
& = \begin{cases}z_{W H}^{*}-z_{N}^{*} & \text { if } 0<z<z_{\alpha} \\
z_{W H}^{*}-z_{N}^{*}+(1 / \alpha) h z_{p}\left(1-1 / 2 z_{p}\right) & \\
-(1 / \alpha) h z_{\alpha}\left(1-1 / 2 z_{\alpha}\right) & \text { if } z_{\alpha}<z<z_{W H}^{*},\end{cases}
\end{aligned}
$$

which is again nondecreasing in $z$, is negative for low enough $z$, and is positive for high enough $z$ (the latter is implied by $\left.m_{N}\left(z_{W H}^{*}\right)<1\right)$. The second part follows immediately, since the matching functions are monotonic and thus invertible. That is, at the same point at which workers are matched with better managers, managers are matched with worse workers. See Figure IV for an illustration.

Proof of Proposition 2. Let us start with the last claim. The difference in the marginal return to skill in the South with and without globalization is given by

$$
\begin{array}{ll}
\sigma_{1 L}-\sigma_{S}+(h / \alpha) z & \text { if } 0<z<\alpha \text { and } h<2(1-\alpha) /\left(2+\alpha-\alpha^{2}\right), \\
\sigma_{1 L}-\sigma_{S}+h & \text { if } \alpha<z<z_{S}^{*} \text { and } h<2(1-\alpha) /\left(2+\alpha-\alpha^{2}\right), \\
\sigma_{1 H}-\sigma_{S} & \text { if } 0<z<z_{\alpha} \text { and } h>2(1-\alpha) /\left(2+\alpha-\alpha^{2}\right), \\
\sigma_{1 H}-\sigma_{S}+(h / \alpha)\left(z-z_{\alpha}\right) & \text { if } z_{\alpha}<z<z_{S}^{*} \text { and } h>2(1-\alpha) /\left(2+\alpha-\alpha^{2}\right) .
\end{array}
$$

It is thus sufficient to show that $\sigma_{1 L}>\sigma_{S}$ and $\sigma_{1 H}>\sigma_{S}$. That $\sigma_{1 L}>$ $\sigma_{S}$ follows directly from the expressions after realizing that $z_{W L}^{*}>z_{S}^{*}$ and $z_{W L}^{*}>1 / 2 \alpha$ in a LQE. For $\sigma_{1 H}>\sigma_{S}$, rewrite (18) as

$$
\sigma_{1 H}=\frac{h z_{W H}^{*}\left(1+1 / 2 h z_{W H}^{*}\right)}{1+h-h z_{W H}^{*}}+\frac{\left(h^{2} / 2 \alpha\right)\left(z_{W H}^{*}-z_{\alpha}\right)^{2}}{1+h-h z_{W H}^{*}}>\sigma_{S},
$$

where the inequality follows since the first term is increasing in $z_{W H}^{*}$ and $z_{W H}^{*}>z_{S}^{*}$, and the second term is positive. This result, combined with $z_{W H}^{*}>z_{S}^{*}$, implies that wage inequality in the South increases with globalization.

Proof of Proposition 3. Simple differentiation of (10) yields

$$
\frac{\partial z_{W L}^{*}}{\partial h}=-\frac{\sqrt{1+h^{2}(3-\alpha)}-1}{h^{2} \sqrt{1+h^{2}(3-\alpha)}}<0,
$$

and differentiation of (15) results in

$$
\begin{aligned}
& \frac{\partial z_{W H}^{*}}{\partial h} \\
& \quad=\frac{1+h+\alpha-h \alpha-(1+\alpha) \sqrt{1+h^{2}+((1-\alpha) /(1+\alpha)) 2 h}}{(\alpha+1) h^{2} \sqrt{1+h^{2}+((1-\alpha) /(1+\alpha)) 2 h}}<0,
\end{aligned}
$$


where the sign follows from

$$
(1+h+\alpha-h \alpha)^{2}-(1+\alpha)^{2}\left(1+h^{2}+\left(\frac{1-\alpha}{1+\alpha}\right) 2 h\right)=-4 \alpha h^{2} .
$$

The conclusions on the set of workers and managers follow directly from this result and the definitions of a $\mathrm{LQE}$ and $\mathrm{HQE}$.

Differentiating $z_{W}^{*}$ with respect to $\alpha$, results in

$$
\frac{\partial z_{W L}^{*}}{\partial \alpha}=\frac{h}{2 \sqrt{1+h^{2}(3-\alpha)}}>0
$$

and

$$
\frac{\partial z_{W H}^{*}}{\partial \alpha}=\frac{2}{(1+\alpha)^{2} \sqrt{\frac{(1+\alpha)\left(1+h^{2}\right)+2 h(1-\alpha)}{1+\alpha}}}>0 .
$$

The last two statements follow from this result as well as from the fact that $z_{W H}^{*} / \alpha$ is decreasing in $\alpha$ (i.e., $\left(\partial z_{W H}^{*} / \partial \alpha\right) \alpha<z_{W H}^{*}$ ), as shown in the proof of Proposition 4.

Proof of Proposition 4. First, consider the effect of $h$ on the quantity of offshoring. The measure of the quantity of offshoring is given by

$$
O_{W}= \begin{cases}1 & \text { if } h<2(1-\alpha) /\left(2+\alpha-\alpha^{2}\right) \\ 1-\left(z_{\alpha} / z_{W H}^{*}\right) & \text { if } h>2(1-\alpha) /\left(2+\alpha-\alpha^{2}\right) .\end{cases}
$$

That is, the quantity of offshoring is the proportion of southern workers in international teams. The quantity of workers engaged in offshoring is in turn given by $\alpha$ in a $\mathrm{LQE}$ and by $z_{W H}^{*}-z_{\alpha}$ in a HQE. We first prove the first statement of the proposition, namely, that $z_{W H}^{*}-z_{\alpha}$ is a decreasing function of $h$. Toward a contradiction, suppose that $z_{W H}^{*}-z_{\alpha}$ is a weakly increasing function of $h$. Then, the number of workers hired by northern managers in $[\alpha, 1]$ weakly increases with $h$. But as we show below in the proof of Proposition 5, firm size (given by $1 / h\left(1-m_{W H}^{-1}(z)\right.$ )) is decreasing in $h$ for any skill level $z_{m}$ of the manager. Hence, since the number of managers in $[\alpha, 1]$ has not changed, the number of workers in their firms must have gone down: a contradiction. Hence $z_{W H}^{*}-z_{\alpha}$ decreases with $h$ or

$$
\frac{\partial z_{W H}^{*}}{\partial h}-\frac{\partial z_{\alpha}}{\partial h}<0 \text {. }
$$


Moving to the first statement of the proposition, notice that since $z_{\alpha}<z_{W}^{*}$, the above inequality implies that

$$
\frac{\partial z_{W H}^{*}}{\partial h} z_{\alpha}<\frac{\partial z_{\alpha}}{\partial h} z_{W H}^{*},
$$

and thus $z_{\alpha} / z_{W}$ is increasing in $h$. This in turn implies that the quantity of offshoring is weakly decreasing in $h$.

We now turn to the effect of $\alpha$ on the quantity of offshoring. Simple differentiation and equation (14) imply that

$$
\begin{aligned}
\frac{\partial\left(z_{\alpha} / z_{W H}^{*}\right)}{\partial \alpha} & =\frac{1}{\left(1-z_{\alpha}\right) h z_{W H}^{* 2}}\left(z_{W H}^{*}\left(1-\frac{\partial z_{W H}^{*}}{\partial \alpha}\right)-h z_{\alpha}\left(1-z_{\alpha}\right) \frac{\partial z_{W H}^{*}}{\partial \alpha}\right) \\
& =\frac{1}{\left(1-z_{\alpha}\right) h z_{W H}^{* 2}}\left(z_{W H}^{*}-\frac{\partial z_{W H}^{*}}{\partial \alpha}\left(\alpha-1 / 2 h z_{\alpha}^{2}\right)\right) \\
& >\frac{1}{\left(1-z_{\alpha}\right) h z_{W H}^{* 2}}\left(z_{W H}^{*}-\alpha \frac{\partial z_{W H}^{*}}{\partial \alpha}\right),
\end{aligned}
$$

and so $\partial\left(z_{\alpha} / z_{W H}^{*}\right) / \partial \alpha>0$ if $z_{W H}^{*}>\alpha\left(\partial z_{W H}^{*} / \partial \alpha\right)$. But simple algebra delivers

$$
\begin{aligned}
z_{W H}^{*} & -\left(\frac{\partial z_{W H}^{*}}{\partial \alpha}\right) \alpha \\
& =\frac{v_{1}(h, \alpha)-v_{2}(h, \alpha)}{h(\alpha+1)^{2} \sqrt{(1 /(\alpha+1))\left(2 h+\alpha-2 h \alpha+h^{2}+h^{2} \alpha+1\right)}},
\end{aligned}
$$

where

$$
\begin{array}{r}
v_{1}(h, \alpha)=(\alpha+1)^{2}(h+1) \\
\times \sqrt{\frac{1}{\alpha+1}\left(2 h+\alpha-2 h \alpha+h^{2}+h^{2} \alpha+1\right)} \\
v_{2}(h, \alpha)=2 h+2 \alpha+2 h \alpha+h^{2}+\alpha^{2}-2 h \alpha^{2}+2 h^{2} \alpha+h^{2} \alpha^{2}+1 .
\end{array}
$$

Now note that $v_{1}(h, \alpha)>v_{2}(h, \alpha)$ if and only if

$$
\begin{aligned}
& v_{1}(h, \alpha)^{2}-v_{2}(h, \alpha)^{2} \\
& \quad=4 \alpha^{2} h\left(h+2 \alpha+h^{2}+\alpha^{2}-2 h \alpha^{2}+2 h^{2} \alpha+h^{2} \alpha^{2}+1\right)>0,
\end{aligned}
$$

which is clearly true. Hence,

$$
\frac{\partial\left(z_{\alpha} / z_{W H}^{*}\right)}{\partial \alpha}>0,
$$


which implies from the definition of $O_{W}$ that the quantity of offshoring is strictly decreasing in $\alpha$.

Finally, we want to show that the measure of workers engaged in offshoring also decreases with $\alpha$; that is,

$$
\frac{\partial\left(\left(z_{W H}^{*}-z_{\alpha}\right) / \alpha\right)}{\partial \alpha}<0 .
$$

To see this, notice that

$$
\begin{aligned}
-\frac{\partial\left(\left(z_{W H}^{*}-z_{\alpha}\right) / \alpha\right)}{\partial \alpha} & =\frac{1}{\alpha^{2}}\left(\left[z_{W H}^{*}-\frac{\partial z_{W H}^{*}}{\partial \alpha} \alpha\right]+\left[\frac{\alpha}{h\left(1-z_{\alpha}\right)}\left(1-\frac{\partial z_{W H}^{*}}{\partial \alpha}\right)-z_{\alpha}\right]\right) \\
& >\frac{1}{\alpha^{2} h\left(1-z_{\alpha}\right)}\left(\alpha\left(1-\frac{\partial z_{W H}^{*}}{\partial \alpha}\right)-h z_{\alpha}\left(1-z_{\alpha}\right)\right) \\
& >\frac{1}{\alpha^{2} h\left(1-z_{\alpha}\right)}\left(\alpha\left(1-\frac{\partial z_{W H}^{*}}{\partial \alpha}\right)-h z_{\alpha}\left(1-1 / 2 z_{\alpha}\right)\right) \\
& =\frac{1}{\alpha^{2} h\left(1-z_{\alpha}\right)}\left(\alpha\left(1-\frac{\partial z_{W H}^{*}}{\partial \alpha}\right)-\left(\alpha-z_{W H}^{*}\right)\right)>0,
\end{aligned}
$$

where we have used twice that $z_{W H}^{*}>\alpha\left(\partial z_{W H}^{*} / \partial \alpha\right)$ as well as $m_{W H}\left(z_{\alpha}\right)=\alpha$.

Proof of Proposition 5. From Proposition 3, a decrease in $h$ increases $z_{W}^{*}$, say from $z_{W 0}^{*}$ to $z_{W 1}^{*}$. From the boundary condition $m_{W}(0)=z_{W}^{*}$, it follows that the worst agent is matched with a better manager. Similarly, the boundary condition $m_{W}\left(z_{W}^{*}\right)=1$ implies that the match for workers with $z_{p}=z_{W 0}^{*}$ worsens. It remains to show that the change in the match is a monotonic function of the skill of the worker. But simple inspection of the formulas for $m_{W L}\left(z_{p}\right)$ and $m_{W H}\left(z_{p}\right)$ reveals that $\partial^{2} m_{W L}\left(z_{p}\right) /$ $\partial h \partial z_{p}>0$ because $z_{p}\left(1-1 / 2 z_{p}\right)$ is increasing in $z_{p}$. To prove the second claim, we need to show that $h\left(1-m_{W}^{-1}\left(z_{m}\right)\right)$ increases in $h$ for all $z_{m}$ in $\left[z_{W}^{*}, 1\right]$. This amounts to computing these partial derivatives for each segment of each equilibrium and showing that they are positive. Simple but tedious derivation then confirms the first result.

To understand the effect of changes in $\alpha$, note that making use of the boundary conditions as well $\partial z_{W L}^{*} / \partial \alpha>0$, it is straightforward to see that the least-skilled worker is matched with a better manager, while the ex ante most-skilled worker is matched with a worse manager. For claim (i), it remains to show that the change in the match is a monotonic function of the skill of the 
worker; i.e., $\partial^{2} m_{W}\left(z_{p}\right) / \partial \alpha \partial z \leq 0$. Again, this is clear from inspection of the formulas for $m_{W L}(z)$ and $m_{W H}(z)$ because $z(1-1 / 2 z)$ is increasing in $z_{p}$. Hence, for each equilibrium, there exist a thresholds $\varphi_{i}<z_{W j}^{*}, j=H, L$, such that all workers with $z<\varphi_{j}$, are matched with a better manager, while all workers with $z>\varphi_{j}$ are matched with a worse manager.

A corollary of this result is that all managers with skill below $m_{W j}\left(\varphi_{j}\right)$ are matched with lower-skilled workers, while all managers with skill above $m_{W j}\left(\varphi_{j}\right)$ are matched with higher-skilled workers. This immediately delivers claim (ii) because remember that firm size is the inverse of $h\left(1-m_{W}^{-1}\left(z_{m}\right)\right)$.

For claims (iii) and (iv), notice that $\partial^{2} m_{W L}(z) / \partial \alpha \partial z=0$ for $\alpha<z<z_{W L}^{*}$ which implies (given the effect on the boundary agents) that $0<\varphi_{L}<\alpha$. Similarly, $\partial^{2} m_{W H}(z) / \partial \alpha \partial z=0$ for $0<$ $z_{p}<z_{\alpha}$ implies that $z_{\alpha}<\varphi_{H}<z_{W H}^{*}$. By the monotonicity of $m_{W}(z)$, these inequalities in turn imply $z_{W L}^{*}<m_{W L}\left(\varphi_{L}\right)<$ $m_{W L}(\alpha)$ and $\alpha<m_{W H}\left(\varphi_{H}\right)<1$. To see that this is sufficient for claims (iii) and (iv), simply remember that the interval of managers that offshore in each equilibrium is $\left(z_{W L}^{*}, m_{W L}(\alpha)\right)$ and $(\alpha$, $1)$, respectively; while the interval of nonoffshorers is $\left(m_{W L}(\alpha), 1\right)$ and $\left(z_{W H}^{*}, \alpha\right)$, respectively.

HARVARD UNIVERSITY

UNIVERSITY OF CHICAGO

PRINCETON UNIVERSITY

\section{REFERENCES}

Acemoglu, Daron, "Patterns of Skill Premia," Review of Economic Studies, LXX (2003), 199-230.

Aitken, Brian, Gordon H. Hanson, and Ann E. Harrison, "Wages and Foreign Ownership: A Comparative Study of Mexico, Venezuela, and the United States," Journal of International Economics, XL (1996), 345-371.

Antràs, Pol, "Firms, Contracts, and Trade Structure," Quarterly Journal of Economics, CXVIII (2003), 1375-1418.

_- "Incomplete Contracts and the Product Cycle," American Economic Review, XCV (2005), 1054-1073.

Antràs, Pol, and Elhanan Helpman, "Global Sourcing," Journal of Political Economy, CXII (2004), 552-580.

Antràs, Pol, Luis Garicano, and Esteban Rossi-Hansberg, "Offshoring in a Knowledge Economy," National Bureau of Economic Research Working Paper No. 11094, January 2005.

Antràs, Pol, Luis Garicano, and Esteban Rossi-Hansberg, "Extensive Offshoring: The Role of Middle Management," mimeo, Harvard University, January 2006.

Autor, David H., Lawrence F. Katz, and Melissa S. Kearney, "Trends in U. S. Wage Inequality: Re-Assessing the Revisionists," mimeo, Massachusetts Institute of Technology, 2004.

Autor, David H., Frank Levy, and Richard J. Murname, "The Skill Content of Recent Technological Change: An Empirical Exploration," Quarterly Journal of Economics, CXVIII (2003), 1279-1334. 
Bernard, Andrew, Raymond Robertson, and Peter Schott, "Is Mexico a Lumpy Country?" National Bureau of Economic Research Working Paper No. 10898, November 2004.

Feenstra, Robert C., and Gordon H. Hanson, "Foreign Investment, Outsourcing and Relative Wages," in Robert C. Feenstra, Gene M. Grossman, and Douglas A. Irwin, eds., Political Economy of Trade Policy: Essays in Honor of Jagdish Bhagwati (Cambridge, MA: MIT Press, 1996a), pp. 89-127.

Feenstra, Robert C., and Gordon H. Hanson, "Globalization, Outsourcing, and Wage Inequality,” American Economic Review, LXXXVI (1996b), 240-245.

Feenstra, Robert C., and Gordon H. Hanson, "Foreign Direct Investment and Relative Wages: Evidence from Mexico's Maquiladoras," Journal of International Economics, XLII (1997), 371-393.

Feenstra, Robert C., and Gordon H. Hanson, "The Impact of Outsourcing and High-Technology Capital on Wages: Estimates for the United States, 19721990," Quarterly Journal of Economics, CXIV (1999), 907-940.

Feenstra, Robert C., and Gordon H. Hanson, "Global Production Sharing and Rising Inequality: A Survey of Trade and Wages," in E. Kwan Choi and James Harrigan, eds., Handbook of International Trade (Oxford, UK: Basil-Blackwell, 2003), pp. 146-185.

Garicano, Luis, "Hierarchies and the Organization of Knowledge in Production," Journal of Political Economy, CVIII (2000), 874-904.

Garicano, Luis, and Esteban Rossi-Hansberg, "Organization and Inequality in a Knowledge Economy," National Bureau of Economic Research Working Paper No. 11458, June 2005.

Garicano, Luis, and Esteban Rossi-Hansberg, "Inequality and the Organization of Knowledge," American Economic Review, Papers and Proceedings, XCIV (2004), 197-202.

Goldberg, Pinelopi Koujianou, and Nina Pavcnik, "Trade, Inequality, and Poverty: What Do We Know? Evidence from Recent Trade Liberalization Episodes in Developing Countries," in Susan M. Collins and Dani Rodrik, eds., Brookings Trade Forum, 2004: Globalization, Poverty, and Inequality (Washington, DC: Brookings Institution Press, 2004), pp. 223-269.

Grossman, Sanford J., and Oliver D. Hart, "The Costs and Benefits of Ownership: A Theory of Vertical and Lateral Integration," Journal of Political Economy, XCIV (1986), 691-719.

Grossman, Gene M., and Elhanan Helpman, "Managerial Incentives and the International Organization of Production," Journal of International Economics, LXIII (2004), 237-262.

Grossman, Gene M., and Giovanni Maggi, "Diversity and Trade," American Economic Review, XC (2000), 1255-1275.

Hanson, Gordon H., and Ann E. Harrison, "Trade Liberalization and Wage Inequality in Mexico," Industrial and Labor Relations Review, LII (1999), 271-288.

Helpman, Elhanan, "A Simple Theory of International Trade with Multinational Corporations," Journal of Political Economy, XCII (1984), 451-471.

Helpman, Elhanan, Marc J. Melitz, and Stephen R. Yeaple, "Exports versus FDI with Heterogeneous Firms," American Economic Review, XCIII (2004), $300-316$.

Holmström Bengt, and Paul R. Milgrom, "The Firm as an Incentive System," American Economic Review, LXXXIV (1994), 972-991.

Kremer, Michael, and Eric Maskin, "Wage Inequality and Segregation by Skill," mimeo, Harvard University, 1997.

Kremer, Michael, and Eric Maskin, "Globalization and Inequality," mimeo, Harvard University, 2003.

Lawrence, Robert Z., and Matthew J. Slaughter, "International Trade and American Wages: Great Sucking Sound or Small Hiccup?" Brookings Papers on Economic Activity, 2 (1993), 161-210.

Lipsey, Robert E., and Frederik Sjoholm, "Foreign Direct Investment, Education and Wages in Indonesian Manufacturing," Journal of Development Economics, LXXIII (2004), 415-422.

Lucas, Jr., Robert, "On the Size Distribution of Business Firms," Bell Journal of Economics, IX (1978), 508-523. 
Manasse, Paolo, and Alessandro Turrini, “Trade, Wages, and 'Superstars', Journal of International Economics, LIV (2001), 97-117.

Melitz, Marc J., "The Impact of Trade on Intra-Industry Reallocations and Aggregate Industry Productivity," Econometrica, LXXI (2003), 1695-1725.

Murphy, Kevin M., and Finis Welch, "Wage Differentials in the 1990s: Is the Glass Half-Full or Half-Empty?" in Finis Welch, ed., The Causes and Consequences of Increasing Inequality (Chicago, IL: University of Chicago Press, 2001), pp. 341-364.

Nocke, Volker, and Stephen R. Yeaple, "An Assignment Theory of Foreign Direct Investment," mimeo, University of Pennsylvania, 2004.

Rosen, Sherwin, "Authority, Control and the Distribution of Earnings," Bell Journal of Economics, XIII (1982), 311-323.

Sattinger, Michael J., "Assignment Models of the Distribution of Earnings," Journal of Economic Literature, XXXI (1993), 831-880.

Verhoogen, Eric A., "Trade, Quality Upgrading and Wage Inequality in the Mexican Manufacturing Sector: Theory and Evidence from an Exchange Rate Shock," mimeo, University of California at Berkeley, 2004.

Waldman, Michael, "Worker Allocation, Hierarchies and the Wage Distribution," Review of Economic Studies, LI (1984), 95-109.

Yeaple, Stephen R., "A Simple Model of Firm Heterogeneity, International Trade, and Wages," Journal of International Economics, LXV (2005), 1-20.

Zhu, Susan C., and Daniel Trefler, "Trade and Inequality in Developing Countries: A General Equilibrium Analysis," Journal of International Economics, LXV (2005), 21-48. 